\title{
Schwann Cell 0-GlcNAc Glycosylation Is Required for Myelin Maintenance and Axon Integrity
}

\author{
몬 \\ Alma L. Burlingame, ${ }^{3}$ and Jeffrey Milbrandt ${ }^{1,2}$ \\ ${ }^{1}$ Department of Genetics and ${ }^{2}$ Hope Center for Neurological Diseases, Washington University School of Medicine, St. Louis, Missouri 63110, \\ ${ }^{3}$ Department of Pharmaceutical Chemistry, University of California, San Francisco, San Francisco, California 94158-2517, and ${ }^{4}$ Centre for \\ Neuroregeneration, University of Edinburgh, Edinburgh EH16 4SB, United Kingdom
}

Schwann cells (SCs), ensheathing glia of the peripheral nervous system, support axonal survival and function. Abnormalities in SC metabolism affect their ability to provide this support and maintain axon integrity. To further interrogate this metabolic influence on axon-glial interactions, we generated OGT-SCKO mice with SC-specific deletion of the metabolic/nutrient sensing protein 0-GlcNAc transferase that mediates the 0 -linked addition of $\mathrm{N}$-acetylglucosamine (GlcNAc) moieties to Ser and Thr residues. The OGT-SCKO mice develop tomaculous demyelinating neuropathy characterized by focal thickenings of the myelin sheath (tomacula), progressive demyelination, axonal loss, and motor and sensory nerve dysfunction. Proteomic analysis identified more than 100 0-GlcNAcylated proteins in rat sciatic nerve, including Periaxin (PRX), a myelin protein whose mutation causes inherited neuropathy in humans. PRX lacking O-GlcNAcylation is mislocalized within the myelin sheath of these mutant animals. Furthermore, phenotypes of OGT-SCKO and Prxdeficient mice are very similar, suggesting that metabolic control of PRX 0-GlcNAcylation is crucial for myelin maintenance and axonal integrity.

Key words: CMT; 0-GlcNAc; OGT; Periaxin; Schwann cell; tomacula

Significance Statement

The nutrient sensing protein O-GlcNAc transferase (OGT) mediates post-translational O-linked $\mathrm{N}$-acetylglucosamine (GlcNAc) modification. Here we find that OGT functions in Schwann cells (SCs) to maintain normal myelin and prevent axonal loss. SC-specific deletion of OGT (OGT-SCKO mice) causes a tomaculous demyelinating neuropathy accompanied with progressive axon degeneration and motor and sensory nerve dysfunction. We also found Periaxin (PRX), a myelin protein whose mutation causes inherited neuropathy in humans, is 0-GlcNAcylated. Importantly, phenotypes of OGT-SCKO and Prx mutant mice are very similar, implying that compromised PRX function contributes to the neuropathy of OGT-SCKO mice. This study will be useful in understanding how SC metabolism contributes to PNS function and in developing new strategies for treating peripheral neuropathy by targeting SC function.

\section{Introduction}

Schwann cells (SCs) ensheath peripheral axons and ultimately support axonal survival and function (Corfas et al., 2004). SC

Received April 13, 2016; revised June 21, 2016; accepted July 25, 2016.

Author contributions: S.K., J.C.M., A.B., and J.M. designed research; S.K., J.C.M., Y.S., and A.S. performed research; Y.S., D.L.S., and P.J.B. contributed unpublished reagents/analytic tools; S.K., J.C.M., Y.S., A.S., A.B., and J.M. analyzed data; S.K. and J.M. wrote the paper.

This work was supported by NIH-National Institute of General Medical Sciences (NIGMS) Award T32GM108539 (S.K.); NIH Grants NS087306 (J.M.) and AG13730 (J.M.); Muscular Dystrophy Association Grant 237041 (J.M.); and the Hope Center for Neurological Disorders, Washington University. Mass spectrometry was provided by the BioOrganic Biomedical Mass Spectrometry Resource at University of California, San Francisco (A. L. Burlingame, director) and supported by the Biomedical Technology Research Centers program of the NIH-NIGMS, NIH-NIGMS Grant 8P41GM103481, and the Howard Hughes Medical Institute. We thank Nina Pachenko, Kelli Simburger, Kimberly Kruse, and members of the Milbrandt laboratory for experimental assistance, comments on this manuscript, and helpful discussions; Shreya Chand for mass spectrometry sample processing; Wandy Beatty for electron microscope abnormalities are implicated in peripheral neuropathy (PN), including the common inherited neuropathies Charcot-MarieTooth type 1 (CMT1) and hereditary neuropathy with liability to pressure palsy (HNPP). Despite the identification of many genetic and environmental causes of PN, the mechanisms by which SCs promote axon integrity remain elusive. Recently, we and others showed that perturbations of SC metabolism in mice, such as those caused by mitochondrial dysfunction or loss of crucial

sample processing; Steven P. Jones for the Ogt loxP mice; and Lawrence Wrabetz and Albee Messing for the Mpz-Cre mice.

The authors declare no competing financial interests.

Correspondence should be addressed to Dr. Jeffrey Milbrandt, Department of Genetics, Washington University School of Medicine, St. Louis, M0 63110. E-mail: jmilbrandt@wustl.edu.

DOI:10.1523/JNEUROSCI.1235-16.2016

Copyright $\odot 2016$ the authors $\quad 0270-6474 / 16 / 369633-14 \$ 15.00 / 0$ 
energy sensors, lead to axonal loss and peripheral neuropathy (Nave, 2010; Viader et al., 2011, 2013; Fünfschilling et al., 2012; Beirowski et al., 2014; Norrmén et al., 2014; Pooya et al., 2014; Shen et al., 2014). These observations indicate that SC metabolism plays a crucial role in the ability of these glial cells to promote axon health and implicate them in the development of neuropathies of metabolic etiology, such as diabetic peripheral neuropathy.

Metabolic interactions between axons and SCs are thought to involve Cajal bands, the SC cytoplasm-filled channels present along myelinated fibers (Nave, 2010). Periaxin (PRX), an abundantly expressed SC protein, mediates the formation of Cajal bands via promoting the abaxonal apposition of compact myelin and SC plasma membrane. PRX is concentrated at the abaxonal (outer surface) appositions where it interacts with dystrophinrelated protein 2 (DRP2; Sherman et al., 2001). Studies of Prx null mice demonstrated a crucial role of PRX in maintaining myelin stability and controlling internodal length (Gillespie et al., 2000; Court et al., 2004). Importantly, human PRX mutations are linked to autosomal recessive peripheral neuropathies CMT4F and Dejerine-Sotas syndrome (DSS), whose main morphological features include focal myelin thickening (tomacula) and progressive demyelination (Renouil et al., 2013).

O-GlcNAcylation is a post-translational modification in which a single GlcNAc moiety is attached to Ser or Thr residues via an O-linkage (Hart and Akimoto, 2009; Bond and Hanover, 2013). O-GlcNAcylation occurs on thousands of proteins and is involved in a wide range of cellular activities, including epigenetic chromatin modification, transcriptional regulation, and signal transduction (Vosseller et al., 2006; Ozcan et al., 2010; Trinidad et al., 2012; Hahne et al., 2013). The GlcNAc addition is catalyzed by O-GlcNAc transferase (OGT), whereas the removal of the GlcNAc moiety from the modified Ser/Thr residue is performed by O-GlcNAcase (OGA, also known as MGEA5; Bond and Hanover, 2015). UDP-GlcNAc, the substrate of OGT, is synthesized in the hexosamine biosynthetic pathway (HBP), using fructose5-phosphate (a glucose derivative), glutamine, acetyl-CoA, and UTP. The coupling of O-GlcNAcylation to the metabolic flux of HBP suggests an important role for OGT as a cellular metabolic/ nutrient sensor. Furthermore, this unique form of intracellular glycosylation has been implicated in diverse human metabolic syndromes and disorders such as diabetes, cancer, and neurodegenerative diseases (Bond and Hanover, 2013).

We hypothesized that O-GlcNAcylation of key SC proteins would reflect the metabolic state of these glial cells and could play an important role in their ability to provide axonal support. To test this idea, we generated mice with SC-specific deficiency of OGlcNAcylation by excising the OGT gene exclusively in SCs (hereafter called OGT-SCKO mice). OGT-SCKO mice display functional and morphological phenotypes of demyelinating, tomaculous peripheral neuropathy. We also analyzed the O-GlcNAcylated proteome of rat sciatic nerve using mass spectrometry (MS). Importantly, we identified PRX as an O-GlcNAcylated protein and found that its localization and function is abnormal in OGT-SCKO mice. PRX is a myelin protein that is mutated in patients with CMT4F, and Prx mutant mice have a neuropathy with nerve pathology that is very similar to that observed in OGT-SCKO mice. In summary, these studies demonstrate a critical role for SC O-GlcNAcylation in the etiology of peripheral neuropathy.

\section{Materials and Methods}

Generation of OGT-SCKO mice. All animal experiments were performed in compliance with institutional animal protocols. OGT-SCKO mice
$\left(\mathrm{P}_{0}-\mathrm{Cre}^{-/+}, O G T^{\text {loxP/loxP}}\right)$ and control $(\mathrm{Ctrl})$ littermates $\left(\mathrm{P}_{0}-\mathrm{Cre}^{-/-}\right.$, $O G T^{\text {loxP/loxP }}$ ) were generated by crossing OGT ${ }^{\text {loxP/loxP }}$ mice (O'Donnell et al., 2004) to $P_{0}$-Cre mice (Feltri et al., 1999). In all experiments, mice of either sex were used. Mating and genotyping were performed as described previously (Viader et al., 2013).

Rotarod test. An accelerating rotarod was used to evaluate motor coordination and balance. Five consecutive acceleration trials were performed with a 5 min interval between trials as described previously (Viader et al., 2011).

Motor and sensory nerve conduction studies. Motor nerve conduction studies were performed on mice monthly (up to 8 months old) using a Viking Quest electromyography machine (Thermo Fisher Scientific) as described previously (Viader et al., 2011). Briefly, mice were anesthetized with Avertin and placed on a heating pad. For nerve electrophysiology, subcutaneous platinum subdermal EEG electrodes $(0.4 \mathrm{~mm}$ diameter, 12 $\mathrm{mm}$ length; Viasys) were used. Stimulating electrodes were placed at the ankle and the sciatic notch for nerve stimulation. Recording electrodes were placed in the footpad. Evoked compound motor action potentials were obtained using supramaximal stimulation, and the distance between the two sites of stimulating electrodes was used to calculate conduction velocity. For tail sensory nerve conduction studies, the recording electrodes were placed $10 \mathrm{~mm}$ distal to the proximal tip of the tail; the stimulating electrodes were placed $30 \mathrm{~mm}$ distal to the recording electrode; the reference electrodes were $10 \mathrm{~mm}$ distal to the stimulating electrodes; and the ground electrodes were placed between the stimulating and recording electrodes. A train of 15 supramaximal responses to 0.1 ms pulses were recorded and averaged to calculate sensory conduction amplitude and latency.

Nerve histology and morphometry. Sciatic nerves from OGT-SCKO and littermate control mice of different ages were dissected and placed in 3\% glutaraldehyde overnight. After washing with phosphate buffer, nerves were postfixed in $1 \%$ osmium tetraoxide in phosphate buffer overnight at $4^{\circ} \mathrm{C}$. Specimens were then dehydrated in graded alcohols and embedded in 100\% epoxy (Araldite 502). For light microscopy, semithin plastic embedded sections ( $300 \mathrm{~nm}$ thick) were prepared and stained with toluidine blue. For electron microscopy, ultrathin sections $(40-50 \mathrm{~nm})$ were prepared, stained with uranyl acetate and lead citrate, and imaged with a JEOL 1200 electron microscope. All nerves underwent qualitative assessment of neural architecture followed by detailed histomorphometric analysis performed as described previously (Viader et al., 2011). Morphometry was performed using Image $(\mathrm{NIH})$, and data processing was performed using Spotfire (TIBCO).

Immunostaining and confocal microscopy. Sciatic nerves were dissected and fixed in $4 \%$ paraformaldehyde for $1 \mathrm{~h}$ at $4^{\circ} \mathrm{C}$. The fixed nerves were cryopreserved in $30 \%$ sucrose and embedded in Tissue-Tek OCT Compound (Sakura Finetek) before preparing $6 \mu \mathrm{m}$ sections. For analysis of teased nerve fibers, mouse sciatic nerves were dissected and fixed in $4 \%$ paraformaldehyde in PBS for $30 \mathrm{~min}$ at $4^{\circ} \mathrm{C}$. The nerves were washed three times in PBS for $5 \mathrm{~min}$ and desheathed, and nerve bundles were dissected with fine needles in PBS on Fisherbrand Superfrost/Plus microscope slides. Slides were air-dried for at least $2 \mathrm{~h}$ at room temperature and stored at $-20^{\circ} \mathrm{C}$. For immunostaining, frozen sections were washed and blocked in 5\% fish skin gelatin in PBS with $0.2 \%$ Triton for $1 \mathrm{~h}$ at room temperature. Sections were then incubated with a primary antibody diluted in blocking buffer overnight at $4^{\circ} \mathrm{C}$. Secondary antibody incubation was performed at room temperature for $1 \mathrm{~h}$ also in blocking buffer. The immunostained sections were mounted with Vectashield mounting medium with DAPI (Vector Laboratories) for microscopic visualization. Images were captured using an upright microscope equipped for epifluorescence microscopy (Nikon 80i, CoolSnapES camera) and were processed using MetaMorph. Confocal images were acquired with a confocal microscope (model C1; Nikon) and accompanying EZ-C1 software using argon (excitation at $488 \mathrm{~nm}$ ) and $\mathrm{HeNe}$ (excitation at 543 and 633 $\mathrm{nm}$ ) lasers and a $60 \times$ Plan-Apochromat NA 1.4 objective (Nikon) at room temperature. Samples for each experiment were processed using the same confocal gain setting unless otherwise specified. All quantifications were performed with the observer blinded to genotype. Image (NIH) was used for all quantitative manipulation and analysis of images. For the quantification of PRX and myelin basic protein (MBP) distribu- 
tion in cross sections of myelinated fibers, pixel intensities of PRX and MBP on a straight line drawn across the myelin sheath (in a direction from inside/adaxonal to outside/abaxonal) were measured using ImageJ Plot Profile. Measurements were aligned according to the coordinate of peak MBP distribution, and quantification/statistical analyses were performed using Spotfire (TIBCO).

Coimmunoprecipitation and Western blotting. Sciatic nerves were isolated, desheathed in PBS, and immediately frozen in liquid nitrogen. Nerve lysates were prepared by homogenizing the tissue in a lysis buffer containing $150 \mathrm{~mm}$ sodium chloride, $20 \mathrm{~mm}$ Tris-Cl, pH 7.4, 1\% Triton $\mathrm{X}-100,1 \mathrm{~mm}$ EDTA, $1 \mathrm{~mm}$ sodium fluoride, $1 \mathrm{~mm}$ sodium orthovanodate, and complete protease inhibitor cocktail (Sigma). The lysates were clarified by centrifugation at $14,000 \mathrm{rpm}$ for $10 \mathrm{~min}$ at $4^{\circ} \mathrm{C}$ and quantified using the MicroBCA Protein Assay kit (Pierce). For coimmunoprecipitation of DRP2 and PRX, the nerve lysates were precleared with protein A-Sepharose (Sigma) at $4^{\circ} \mathrm{C}$ for $30 \mathrm{~min}$, incubated either with anti-DRP2 or anti-PRX repeat (PRX-R) antibody for $1 \mathrm{~h}$, followed by incubation with protein A-Sepharose for an additional $1 \mathrm{~h}$. O-GlcNAcylation of PRX in HEK 293T cells was analyzed in cells stably expressing FLAG-tagged PRX. These cells were transfected with human OGT expression vector and/or treated with $1 \mu \mathrm{M}$ Thiamet-G. Lysates were prepared, and PRX was immunoprecipitated using FLAG antibody. For Western blotting, the proteins were separated by SDS-PAGE and transferred to a PVDF membrane (Millipore). Membranes were blocked in 5\% milk in $0.05 \%$ PBS-Tween and incubated overnight with the appropriate primary antibody. After incubation with secondary antibodies conjugated to HRP (GE Healthcare), membranes were developed with Western Chemiluminescent HRP Substrate (ECL; EMD Millipore Immobilon). Densitometry of the blots was performed using ImageJ.

Antibodies. The following antibodies were used at the indicated dilution. For Western blot: O-GlcNAc RL2 (1:1000; Abcam), PRX-N (1: 2000; Dytrych et al., 1998), PRX-R (1:10,000; Dytrych et al., 1998), DRP2 (1:3000; Sherman et al., 2001), GAPDH (1:1000; Cell Signaling Technology), $\beta$-actin (1:1000; Sigma), FLAG (1:1000; Sigma), $\beta$-tubulin E7 (1: 1000; Developmental Studies Hybridoma Bank), and Dystroglycan $\alpha$ IIH6 C4 (1:100; Developmental Studies Hybridoma Bank). For immunostaining: O-GlcNAc RL2 (1:200; Novus Biologicals), S100 (1:1000; Dako), MBP (1:1000; Millipore), and NAV1.6 K87A/10 (1:100; UC Davis NeuroMab Facility).

Lectin weak affinity chromatography. Lectin weak affinity chromatography (LWAC) and MS analysis of O-GlcNAc proteome was described previously (Vosseller et al., 2006; Trinidad et al., 2012). Briefly, rat sciatic nerves from four adult rats (6 months old) were isolated, desheathed in ice-cold PBS, and flash-frozen in liquid nitrogen. Frozen tissues were mixed with $500 \mu \mathrm{l}$ of Trizol reagent (Ambion, Life Technologies) and lysed by sonication on ice, and proteins were extracted according to the manufacturer's protocol. The resulting protein pellets were solubilized in $8 \mathrm{~m}$ urea, $0.2 \%$ Zwittergent 3-16 (Calbiochem), $100 \mathrm{~mm}$ ammonium bicarbonate, $\mathrm{pH} 8.0,4 \times$ Phosphatase Inhibitor Cocktails I and III (Sigma), and $20 \mu \mathrm{M}$ PUGNAc. The mixture was reduced for $30 \mathrm{~min}$ at $57^{\circ} \mathrm{C}$ with $5 \mathrm{~mm}$ dithiothreitol and subsequently carbamidomethylated using $10 \mathrm{~mm}$ iodoacetamide for $30 \mathrm{~min}$ at room temperature in the dark. Lysates were diluted to $2 \mathrm{M}$ urea with $100 \mathrm{~mm}$ ammonium bicarbonate, $\mathrm{pH} 8.0$, and digested overnight at $37^{\circ} \mathrm{C}$ with sequencing-grade trypsin (Promega) at an enzyme-to-substrate ratio of 1:50 (w/w). After digestion, samples were acidified with formic acid (Sigma-Aldrich) and subsequently desalted using a $360 \mathrm{mg}$ C18 Sep-Pak SPE cartridge (Waters). Desalted samples were dried to completeness using a SpeedVac concentrator (Thermo Electron). Desalted sciatic nerve tryptic peptides were resuspended in $400 \mu \mathrm{l}$ of LWAC buffer (100 mm Tris, $\mathrm{pH}$ 7.5, $150 \mathrm{~mm}$ $\mathrm{NaCl}, 10 \mathrm{~mm} \mathrm{MgCl}_{2}, 10 \mathrm{~mm} \mathrm{CaCl}_{2}$, and 5\% acetonitrile). Glycopeptides were enriched with a POROS-WGA column, collected, and desalted inline using a Luna $10 \mu \mathrm{C} 18$ column (Phenomenex). A total of three rounds of LWAC enrichment were performed. LWAC-enriched glycopeptides were subsequently fractionated by high-pH reverse-phase liquid chromatography.

Mass spectrometry analysis. All samples were analyzed on an Orbitrap Velos (Thermo Fisher Scientific) equipped with a nano-Acquity UPLC (Waters). Peptides were fractionated on a $15 \mathrm{~cm} \times 75 \mu \mathrm{m}$ ID $3 \mu \mathrm{m} \mathrm{C18}$
EASY-Spray column using a linear gradient from 2 to $35 \%$ solvent B over $60 \mathrm{~min}$. Survey mass measurements were performed using the Orbitrap, scanning from $\mathrm{m} / \mathrm{z} 350-2000$. The three most abundant multiply charged ions were computer selected for higher energy collisional dissociation (HCD) and electron transfer dissociation (ETD) analysis. The trigger intensity was set to 2000 . Supplemental activation was enabled. The ETD fragments were measured in the linear trap, whereas HCD fragments were measured in the Orbitrap. Each sample was injected twice; the first analysis selected only $2+$ precursor ions, and in the second analysis, 2+ precursor ions were excluded. Peaklists were extracted using Proteome Discoverer 1.4. ETD data were searched twice against the UniProt Rattus norvegicus database (downloaded June 6, 2013) (and concatenated with a randomized sequence for each entry) using Protein Prospector (version 5.10.15). Cleavage specificity was set as tryptic, allowing for two missed cleavages. Carbamidomethylation of Cys was set as a constant modification. The required mass accuracy was $5 \mathrm{ppm}$ for precursor ions and 0.8 Da for ETD fragments. Both searches included acetylation of protein $\mathrm{N}$ termini; oxidation of Met; cyclization of N-terminal Gln; and HexNAc modification of Ser, Thr, and Asn, as variable modifications. The first search also allowed for the following extended $\mathrm{N}$ linked glycans on Asn: HexNAc2, HexNAc2Hex2, HexNAc2Hex2Fuc, HexNAc2Hex2Fuc, HexNAc2Hex3, HexNAc2Hex3Fuc, HexNAc2Hex4, HexNAc2Hex4Fuc, HexNAc2Hex5, HexNAc2Hex5Fuc, HexNAc2Hex6, HexNAc2Hex7, HexNAc2Hex8, HexNAc2Hex9, HexNAc3Hex3Fuc, HexNAc3Hex5Fuc, HexNAc3Hex5FucSA, HexNAc4Hex3Fuc, HexNAc 4Hex4Fuc2, HexNAc4Hex4SA, HexNAc4Hex5Fuc, HexNAc4Hex5Fuc2, HexNAc4Hex6Fuc, HexNAc5Hex3Fuc, HexNAc5Hex4Fuc, HexNAc5 Hex4Fuc2, HexNAc5Hex4SA, HexNAcFuc. The second search allowed for the following extended O-linked glycans on Ser and Thr: HexNAc2, HexNAc2Hex2, HexNAcFuc, HexNAcHex, HexNAcHexSA, HexNAcHexSA2, HexNAcSA, as well as HexNAc and HexNAc2 on Asn. Three modifications per peptide were permitted. HCD data were searched with the same parameters except that fragment ion mass accuracy was $30 \mathrm{ppm}$ and the only glycans set as variable modifications were HexNAc on Asn, Ser, and Thr and as a neutral loss. Modified peptides were identified with a protein and peptide false discovery rate of $1 \%$. O-GlcNAc and O-GalNAc modifications were differentiated based on protein localization and HexNAc oxonium ion fragment ratios (Halim et al., 2014). Results can be viewed in MS_Viewer [http://prospector2.ucsf.edu/prospector/cgi-bin/msform. cgi?form=msviewer (search keys: ETD, ntrqixzaiv; HCD, fcx3docywo); Baker and Chalkley, 2014].

Statistics. Data are represented as mean \pm SEM, unless otherwise specified. Statistical tests were performed with Spotfire (TIBCO) and Excel 2010 (Microsoft). Groups of means were compared using one-way ANOVA, and comparisons between two means were performed using Student's $t$ test. Significance was as ${ }^{*} p<0.05 ;{ }^{* *} p<0.01{ }^{* * *} p<0.001$; ns, not significant.

\section{Results}

\section{OGT deficiency causes abnormal glucose metabolism in} Schwann cells

OGT is the sole enzyme catalyzing O-GlcNAcylation in mammalian cells. To study the role of O-GlcNAcylation in Schwann cell function and peripheral nerve biology, we generated SC-specific OGT knock-out mice (OGT-SCKO). Mice carrying loxP flanked alleles of OGT ( $O G T^{\text {loxP }}$; Shafi et al., 2000) were crossed with mice expressing Cre recombinase in SCs $\left(\mathrm{P}_{0}\right.$-Cre mice) (Feltri et al., 1999; Shafi et al., 2000). OGTSCKO mice were born at the expected Mendelian ratio and developed normally without any overt morphological or behavioral abnormalities. However, beginning $\sim 6$ months of age they develop gait abnormalities, muscle weakness, and hindlimb clasping, a typical presentation of neuromuscular dysfunction in mice (Fig. 1A).

We examined OGT levels in the mutant nerve, and, as expected, we detected substantially reduced levels of OGT in sciatic nerve lysates from 1-month-old OGT-SCKO mice (Fig. 1B). The 
A

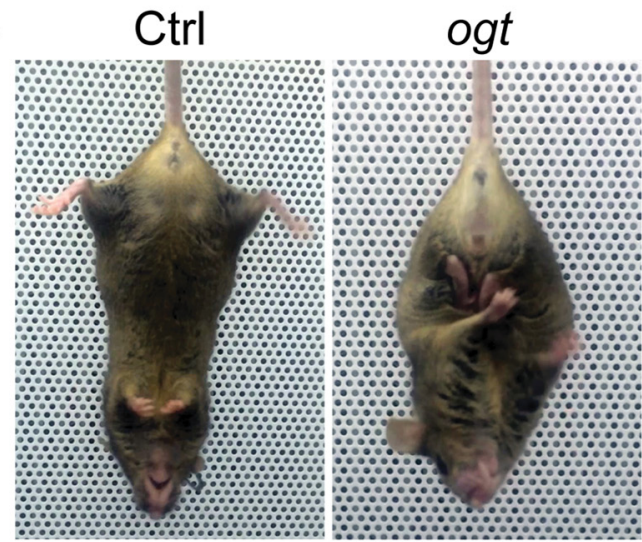

B

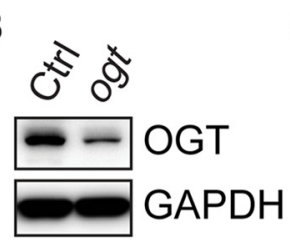

C

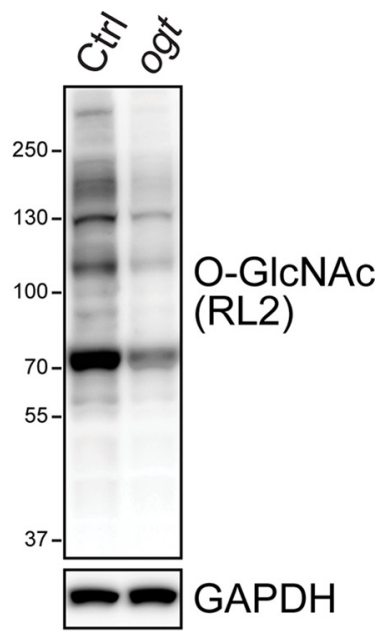

D
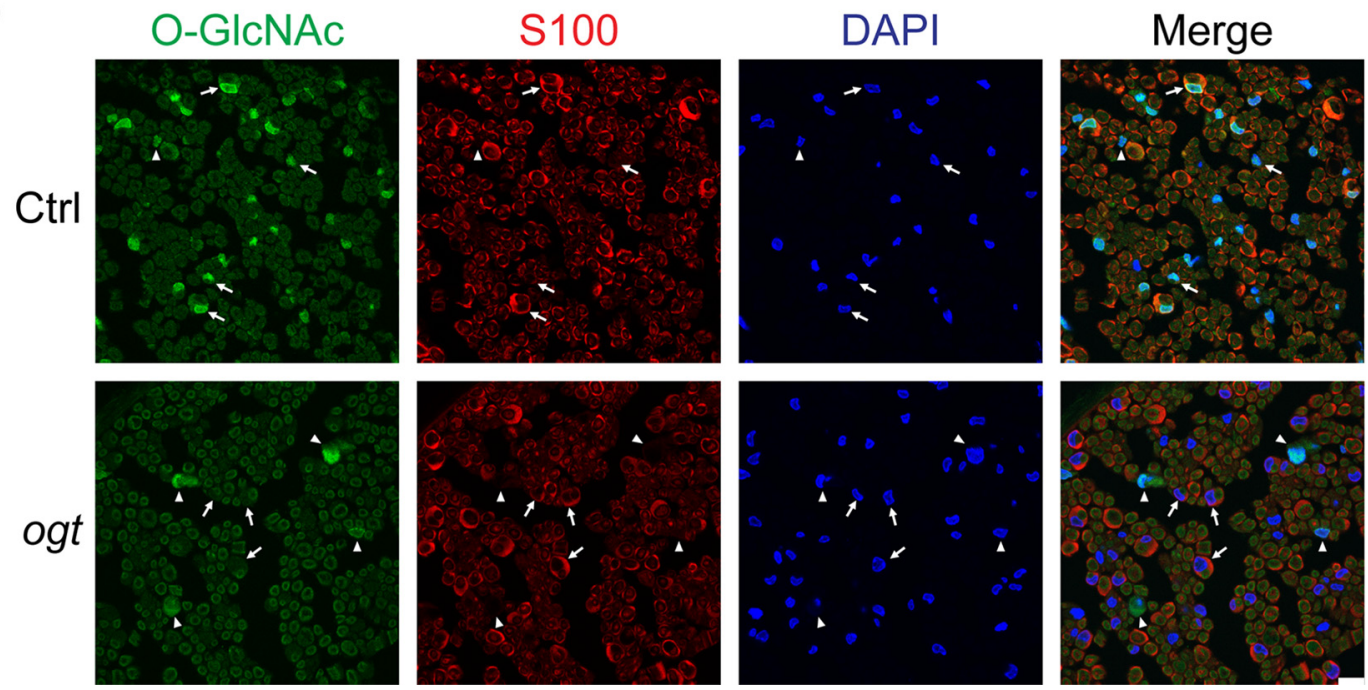

Figure 1. OGT-SCKO mice have deficits in 0-GICNAcylation and glucose metabolism. $A, 0$ GT-SCKO mice at 8 months of age show hindlimb clasping, a common sign of peripheral neuropathy in mice. $\boldsymbol{B}, \boldsymbol{C}$, Western blot analysis of OGT expression ( $\boldsymbol{B}$ ) and 0 -GICNAcylation $(\boldsymbol{C})$ in sciatic nerves from 1-month-old control and OGT-SCKO mice. $\boldsymbol{D}$, Representative confocal microscopic images of sciatic nerves from 1-month-old OGT-SCKO and control mice stained for 0-GICNAC (green), S100 (red), and DAPI (blue). Intense nuclear 0-GIcNAc immunoreactivity is detectable in S100-positive SCS (arrows) and non-SCs (arrowheads) in the control nerve (Ctrl), whereas 0-GICNAcstaining is absent in S100-positive SCs in the 0GT-SCKO nerve (ogt). Note 0-GICNACstaining in non-SCs in the mutant nerve (arrowheads). Scale bar, $10 \mu \mathrm{m}$.

remaining OGT signal in these mutant nerves is likely derived from non-SC elements (e.g., axons and other cell types such as fibroblasts, endothelial cells, and resident macrophages). In concert with the loss of OGT, the levels of total O-GlcNAcylation were similarly decreased in OGT-SCKO nerves (Fig. 1C), indicating that OGT deficiency in SCs results in loss of protein O-GlcNAcylation in these glia. To confirm the loss of OGT specifically in SCs, we performed immunohistochemistry using an anti-O-GlcNAc antibody. Strong O-GlcNAc immunoreactivity was detected in SCs (S100 positive) as well as other cell types (S100 negative) in control sciatic nerves. However, in OGTSCKO nerves, O-GlcNAc staining was lost in the SCs but was still present in the $\mathrm{S} 100$-negative cells (Fig. $1 D$ ), reflecting the successful and specific excision of OGT in SCs. Although OGT is reported to be critical for cell viability and proliferation in many tissues and cell types (Shafi et al., 2000; O'Donnell et al., 2004), we observed no death or altered proliferation in SCs lacking OGT (data not shown).

SC O-GlcNAcylation is required for peripheral nerve function The hindlimb clasping observed in OGT-SCKO mice prompted us to perform additional tests of neuromuscular function. Motor function was evaluated using the rotarod test. We found that OGT-SCKO mice performed poorly on this test with a latency to fall of $40 \pm 10 \mathrm{~s}$ versus $69 \pm 18 \mathrm{~s}$ in littermate controls (Student's $t$ test, $p<0.02$ ). To directly assess peripheral nerve function, we performed motor nerve conduction studies in mice of different ages (Fig. 2). At 1 month of age, compound muscle action potentials (CMAPs) in the sciatic nerve were subtly but significantly delayed in OGT-SCKO mice (Fig. 2A,B). The slowed conduction velocity in these mutant mice deteriorated further with increasing age. It is notable that nerve conduction was relatively stable at $\sim 20 \mathrm{~m} / \mathrm{s}$ until $\sim 3$ months of age but then plummeted dramatically over the next couple of months. This is particularly notable because conduction velocities of wild-type mice typically increase during this period (note increase in control mice from 1 to 5 months of age), coincident with the formation and maturation of compact myelin (Viader et al., 2011; Wu et al., 2012). These results indicate that the deficits in conduction velocity in OGT-SCKO sciatic nerve are likely attributable to myelin abnormalities. In addition to changes in conduction velocity, we also noted a decrease in the CMAP amplitude, an indicator of axonal integrity (Fig. $2 \mathrm{~A}, \mathrm{C}$ ). The diminished CMAP amplitude contin- 
A

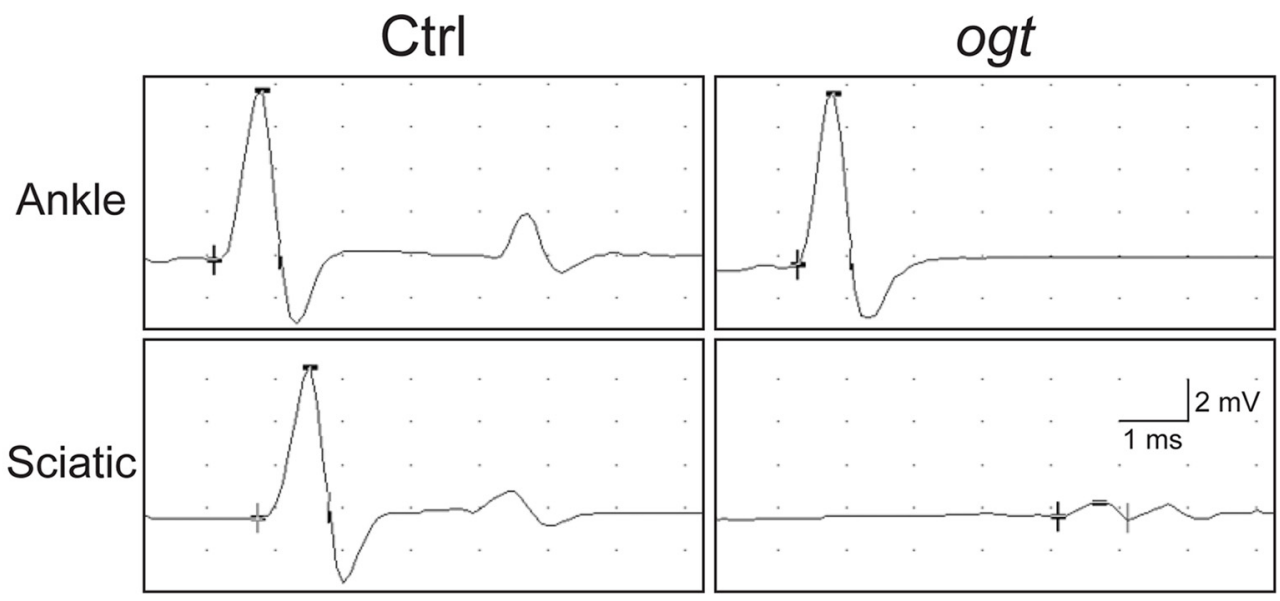

B

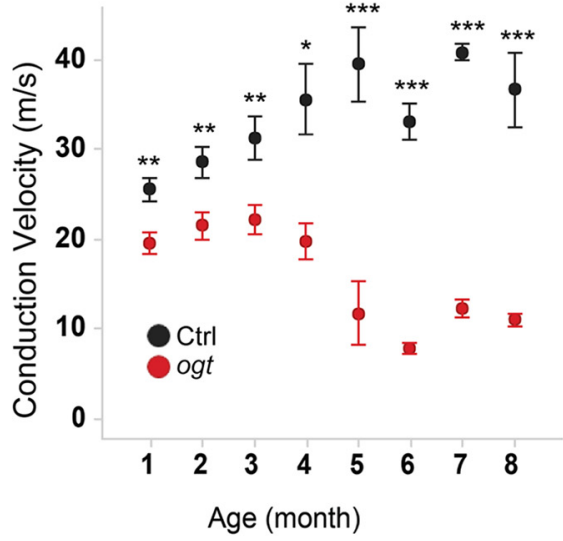

C

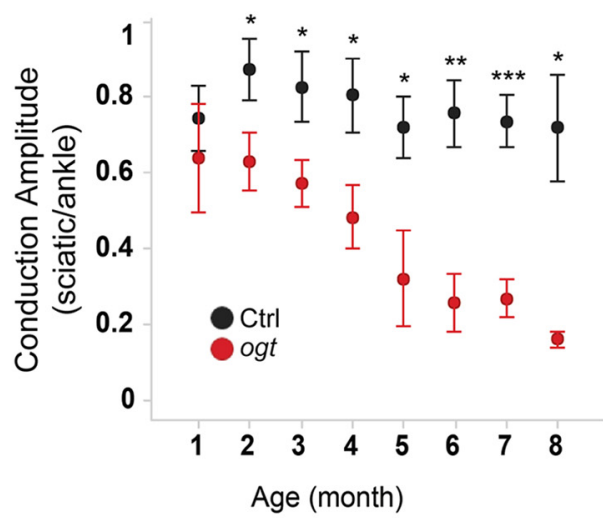

D

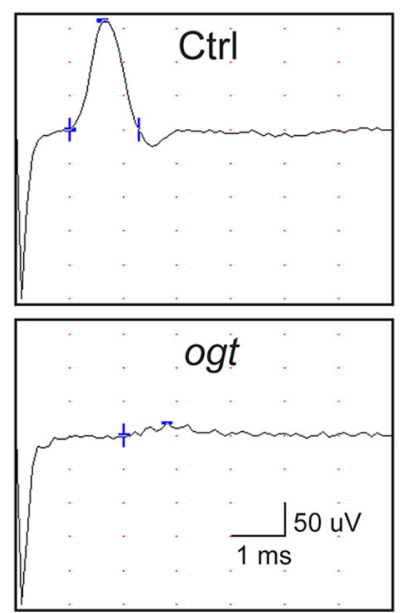

E

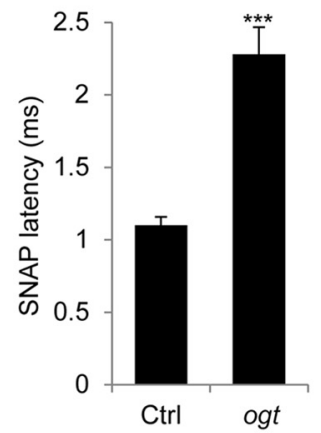

$\mathbf{F}$

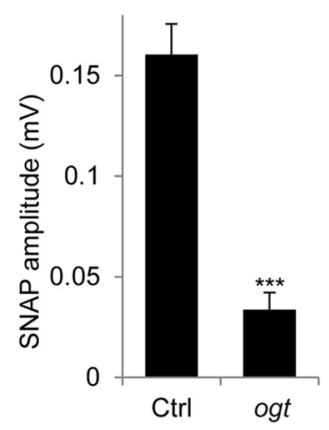

Figure 2. Impaired motor and sensory nerve functions in OGT-SCKO mice. $A-C$, Motor nerve conduction studies performed on OGT-SCKO and littermate control mice at the indicated ages. $\boldsymbol{A}$, Representative traces of CMAP from 6-month-old OGT-SCKO and control mice recorded at the footpad muscle and stimulated either at ankle or at sciatic notch. B, C, Quantification of conduction velocity $(\mathrm{m} / \mathrm{s} ; \boldsymbol{B})$ and amplitude $(\mathrm{mV}$, sciatic/ankle; $\boldsymbol{C})$ at the indicated ages; $n=4-5$ mice per genotype at each age. $\boldsymbol{D}-\boldsymbol{F}$, Sensory nerve conduction studies on 2-month-old control and $0 \mathrm{GT}$-SCKO mice. $\boldsymbol{D}$, Representative traces of tail SNAP. $\boldsymbol{E}, \boldsymbol{F}$, Quantification of SNAP latency $(\mathrm{ms} ; \boldsymbol{E})$ and SNAP amplitude ( $\mathrm{mV} ; \boldsymbol{F}) ; n=3$ mice per genotype. Data represented as mean \pm SEM. Student's $t$ test: ${ }^{* * *} p<0.001 ;{ }^{* *} p<0.01 ;{ }^{*} p<0.05$.

ued to decline in older OGT-SCKO mice, indicating the progressive nature of the underlying axonopathy.

To assess the function of sensory nerves, we measured sensory nerve action potentials (SNAPs) in the tail nerve of 2-month-old OGT-SCKO mice. We found the SNAP signal had increased latency and decreased amplitude compared with littermate controls (Fig. 2D-F) and was virtually undetectable at 3 months of age (data not shown). These results are consis- tent with the presence of both defective myelin and impaired axonal integrity in the sensory nerves of these mutant mice. Interestingly, the total lack of sensory responses in 3-monthold OGT-SCKO mice contrasts sharply with the only slightly diminished motor responses at this age. The earlier appearance of sensory versus motor deficits is similar to that seen in mice in which the SCs lack either liver kinase B1 or mitochondrial transcription factor A (Viader et al., 2013; Beirowski et 
A
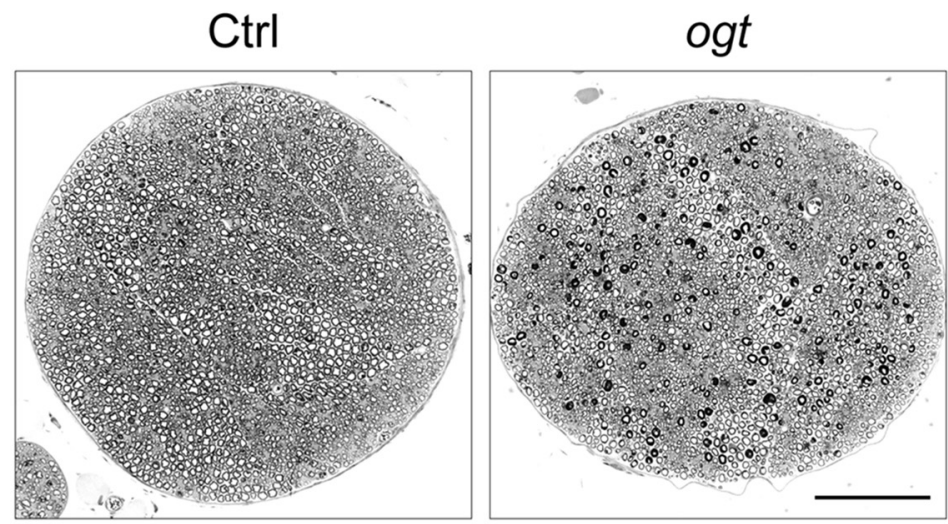

D
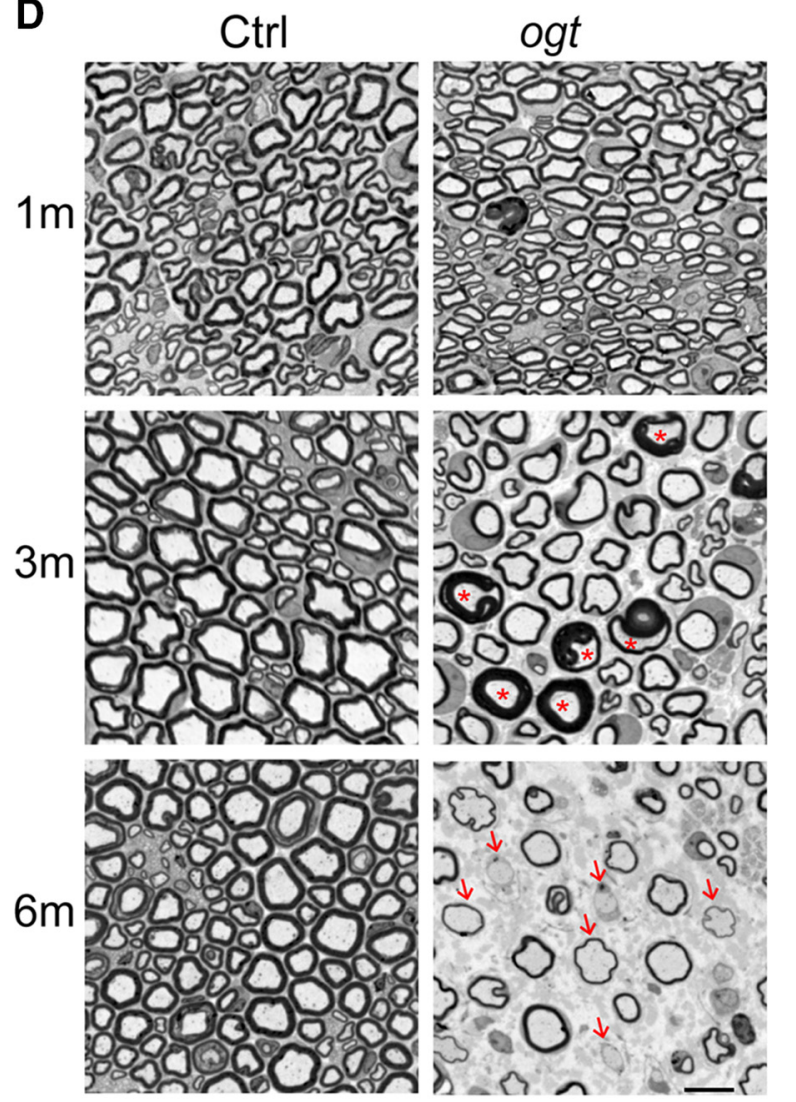

G

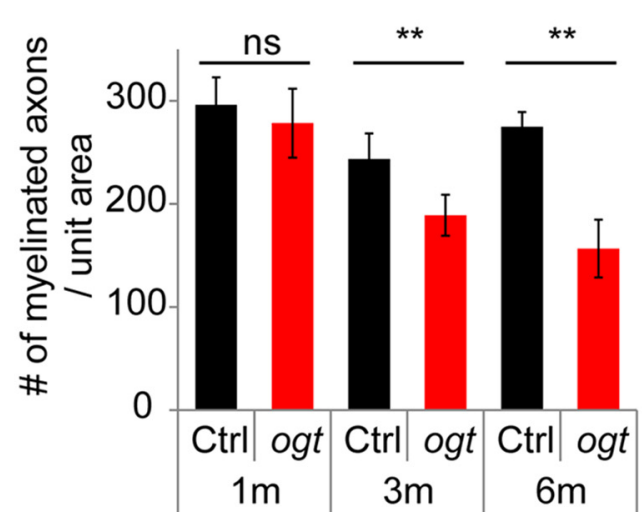

B

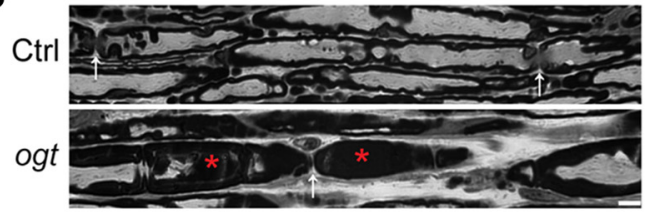

C

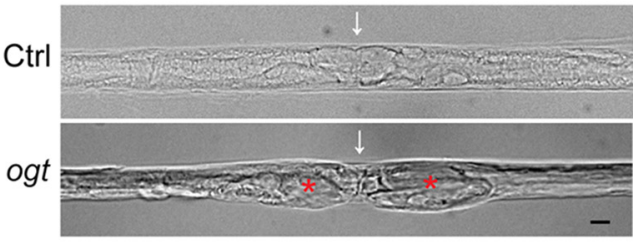

F
E
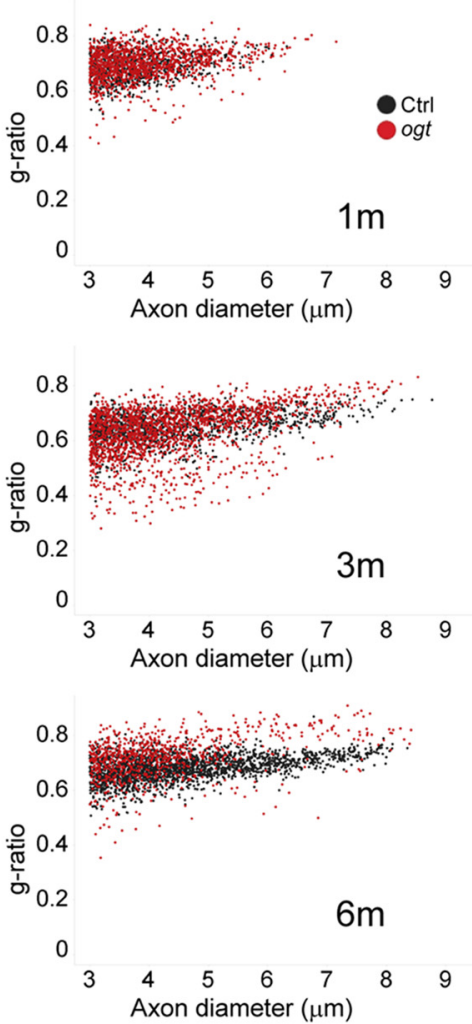

H

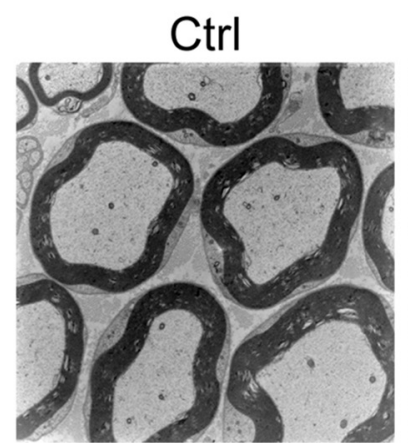

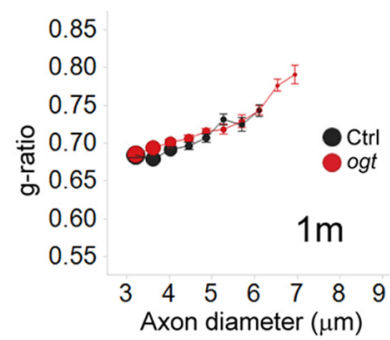
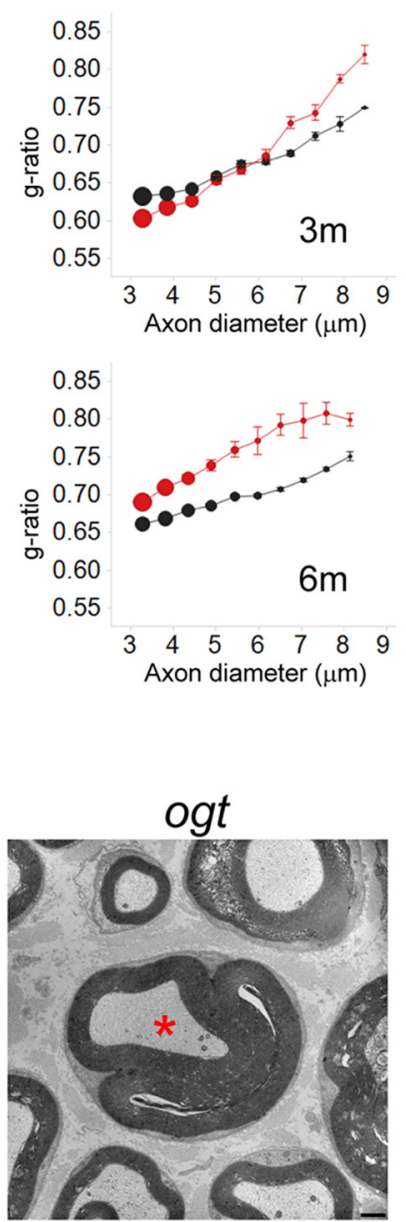

Figure 3. OGT-SCKO mutant mice develop tomaculous demyelinating neuropathy. $\boldsymbol{A}, \boldsymbol{B}$, Toluidine blue-stained semithin cross section $(\boldsymbol{A})$ and longitudinal section $(\boldsymbol{B})$ of sciatic nerves from 3-month-old OGT-SCKO and control mice. $\boldsymbol{A}$, In cross section, note the numerous dark profiles corresponding to tomacula. $\boldsymbol{B}$, In the longitudinal section, (Figure legend continues.) 
al., 2014), supporting the idea that the function and integrity of sensory fibers are more dependent on SC metabolism than are larger motor axons.

\section{OGT-SCKO develop tomaculous demyelinating peripheral neuropathy and axonal loss}

To examine the morphological features that underlie the nerve dysfunction in OGT-SCKO mice, we performed nerve histology and morphometry at various ages (Fig. 3). A macroscopic crosssectional view of the sciatic nerve from OGT-SCKO mice clearly shows the presence of many darkly stained myelin abnormalities consistent with a tomaculous neuropathy (Fig. 3A). Consistent with our functional assays, the appearance of these abnormalities is age dependent: a 1-month-old nerve shows few abnormalities, whereas nerves from older mice show numerous tomacula, or focal thickenings of the myelin sheath, and progressive axonal loss (Fig. 3D-F). The focal thickenings are most frequently observed in the juxtaparanodal/paranodal regions as seen in semithin longitudinal sections and teased fiber preparations of mutant nerve (Fig. $3 B, C$ ). Similar to tomacula formation in human patients and other animal models (Gillespie et al., 2000; Sander et al., 2000), these tomaculous fibers have myelin with abnormal and redundant folds. The ensheathed axons are distorted and of small diameter, characteristics ostensibly attributable to the compressive nature of the myelin in-foldings (Fig. $3 D, H)$. We quantified myelin thickness by calculating the g-ratio, the ratio of the inner axonal diameter to the outer diameter of the myelinated fiber (Fig. $3 E, F$ ). Small-diameter axons in 3-month-old OGT-SCKO nerves had a lower g-ratio compared with nerves in control animals, confirming the association of smaller-caliber axons with thick, tomaculous myelin (Fig. $3 E, F$ ). The larger-diameter axons had a higher g-ratio (thinner myelin) in the mutant animals. Indeed, electron microscopy of these mutant nerves clearly revealed axons surrounded by abnormal and redundant folds of the myelin sheath (Fig. $3 H$ ). At 6 months of age, naked and hypomyelinated nerve fibers prevail in the mutant nerves, consistent with the lower g-ratio for the entire axon profile (Fig. 3D-F). We consistently observed fewer axons in OGTSCKO nerves in sharp contrast to wild-type nerves that are fully occupied by axons. This loss of axons is rapidly progressive as determined by quantification of myelinated axons at multiple ages (Fig. 3G). Interestingly, nerves from OGT-SCKO mice man-

\section{$\leftarrow$}

(Figure legend continued.) note the focal hypermyelination/tomacula (asterisks) at paranodal/juxtaparanodal regions in OGT-SCKO nerves (ogt). Arrows denote the node of Ranvier. Scale bars: $A, 100 \mu \mathrm{m} ; \boldsymbol{B}, 10 \mu \mathrm{m}$. C, Differential interference contrast image of teased sciatic nerve fibers from 3-month-old control and OGT-SCKO mice. White arrows indicate node of Ranvier; red asterisks denote tomacula at paranodal/juxtaparanodal region. Scale bar, $10 \mu \mathrm{m}$. D, Toluidine blue-stained semithin cross sections of sciatic nerves from OGT-SCKO and control mice at 1,3, and 6 months of age. In OGT-SCKO nerves, note the abnormal folds (tomacula) of hypermyelinated fibers (asterisks) at 3 months of age and the naked and hypomyelinated axons (arrows) as well as axonal loss at 6 months of age. Scale bar, $10 \mu \mathrm{m} . \boldsymbol{E}, \boldsymbol{F}$, Scatter plot analysis $(\boldsymbol{E})$ and modified bubble chart $(\boldsymbol{F})$ of $g$-ratio versus axon diameter for the myelinated fibers in $\boldsymbol{D}$. In $\boldsymbol{F}$, axons from 3 to $9 \mu \mathrm{m}$ in diameter are grouped into 10 bins. The g-ratio is represented as mean \pm SEM for each bin. The size of the circle is scaled according to the total number of axons at the indicated size for each genotype; $n=3$ mice per genotype at the indicated age. Note the morphometric profiles of tomaculous small-diameter axons with lower g-ratios as well as hypomyelinated large-diameter axons with higher g-ratios in 3-month-old OGT-SCKO nerves. In 6-month-old OGT-SCKO nerves, axons of all sizes are hypomyelinated as reflected by the higher g-ratio. G, Quantification of the number of myelinated fibers per unit area at the indicated age in $\boldsymbol{D}$. Data are represented as mean \pm SEM. Student's $t$ test, ${ }^{* *} p<0.01 ; n=3$ mice per genotype at each age. $\boldsymbol{H}$, Electron micrograph of sciatic nerve in the cross section from 3-monthold control and OGT-SCKO mice. Tomaculum is indicated by the asterisk. Scale bar, $1 \mu \mathrm{m}$. ifest a significant degree of axonal degeneration at 3 months, an age when there are no signs of demyelination (Fig. $3 D-G$ ), suggesting that axon loss is not a consequence of demyelination. Together, our morphological analyses demonstrate that SC $\mathrm{O}-$ GlcNAcylation is required for the structural integrity and maintenance of myelin as well as the support of peripheral axons. Furthermore, the morphological abnormalities of OGT-SCKO nerves are consistent with the deficits observed in our functional studies (Fig. 2).

\section{Mass spectrometry analysis of the $\mathrm{O}$-GlcNAc proteome from rat sciatic nerves}

More than 3000 O-GlcNAcylated proteins have been identified in various tissues and cell types, but their abundance and significance in the peripheral nervous system is unknown. To identify O-GlcNAcylated proteins in SCs, we established an O-GlcNAc proteome from adult rat sciatic nerves. The O-GlcNAc-modified peptides were enriched using LWAC, and the recovered glycopeptides were subsequently processed for analysis by MS (Trinidad et al., 2012). In the MS analysis, a total of 212 glycosylated $(\mathrm{N}$ - and $\mathrm{O}$-linked) proteins were identified, and 123 of them were O-GlcNAc modified. A total of 295 unique O-GlcNAc peptides were identified with 132 unambiguous sites of modification (dataset available in MS_viewer; see Materials and Methods for details). The majority of O-GlcNAcylated proteins (110 of 123) in rat sciatic nerve are similarly modified in other tissues (Trinidad et al., 2012). Kyoto Encyclopedia of Genes and Genomes pathway analysis on the SN O-GlcNAc proteome indicated enrichment in focal adhesion (Ppp1r12a, Flnb, Itgb4, Itga7, Tln1, and Tln2; Bonferroni's adjusted $p(\operatorname{adjP})=0.0008)$ and MAPK signaling (Hspb1, FlnB, Mapk8ip1, and Tab1; adjP = 0.0492), implicating a potential role of O-GlcNAcylation in cytoskeletal organization, cell motility, proliferation, and survival. In addition, the SN O-GlcNAc proteome includes 16 transcription factors, consistent with O-GlcNAcylationdependent regulation of gene expression (Ozcan et al., 2010).

We also identified a small set of O-GlcNAcylated proteins that appear specific to sciatic nerve as they are not present in our previously analyzed brain synaptosome (Trinidad et al., 2012). These proteins included AMBRA1, EHBP1L1, FILIP1, FOXO1, Irf2bpl, ITGB4, Kansl3, Lin54, MAFK, PAMR1, PLEKHA4, and PRX. Among them, PRX is particularly interesting as an OGT target because it is almost exclusively and abundantly expressed in SCs (Gillespie et al., 1994; Maddala et al., 2011; Patzig et al., 2011). Additionally, mutations in $P R X$ cause a tomaculous demyelinating peripheral neuropathy in humans that appears similar to that observed in OGT-SCKO mice (see below). We mapped five O-GlcNAc modifications of rat PRX at residues T657, T755, T1051, S1052, and T1064, all of which are conserved in human and mouse PRX (Fig. 4A,B). O-GlcNAcylation frequently occurs in the unstructured region of a target protein (Trinidad et al., 2012); accordingly, all of the O-GlcNAc modifications on PRX are located within the repeat and acidic regions that lack any known structural fold. We found no O-GlcNAcylated sites in either the PDZ domain or the basic motif at the $\mathrm{N}$ terminus that directly mediate protein-protein interactions and are thought to guide the subcellular localization of PRX (Gillespie et al., 1994; Scherer et al., 1995; Sherman et al., 2001). To confirm the OGTdependent O-GlcNAcylation of PRX, we performed immunoprecipitation experiments. As expected, PRX from wild-type sciatic nerves was O-GlcNAcylated, whereas no O-GlcNAcylation was detected on PRX from OGT-SCKO nerves (Fig. 4C). In contrast, the PRX interacting protein DRP2 is not O-GlcNAcylated (Fig. $4 D$ ). Finally, we confirmed the O-GlcNAcylation of PRX using FLAG- 
A

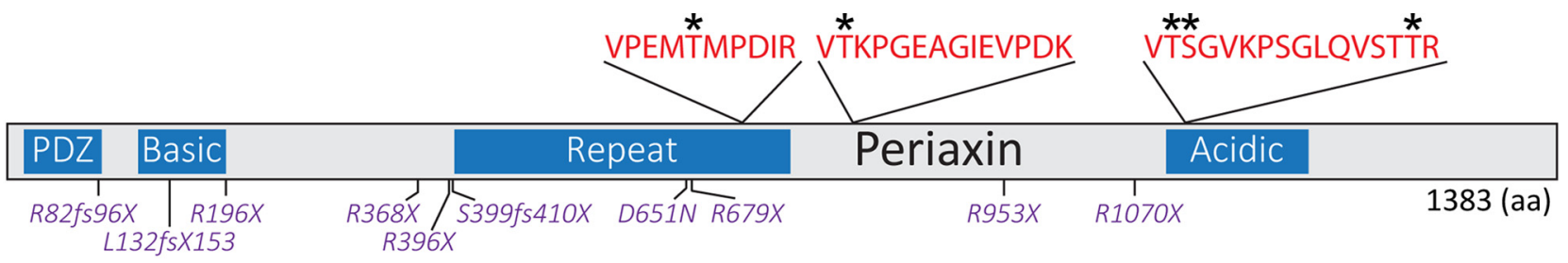

B

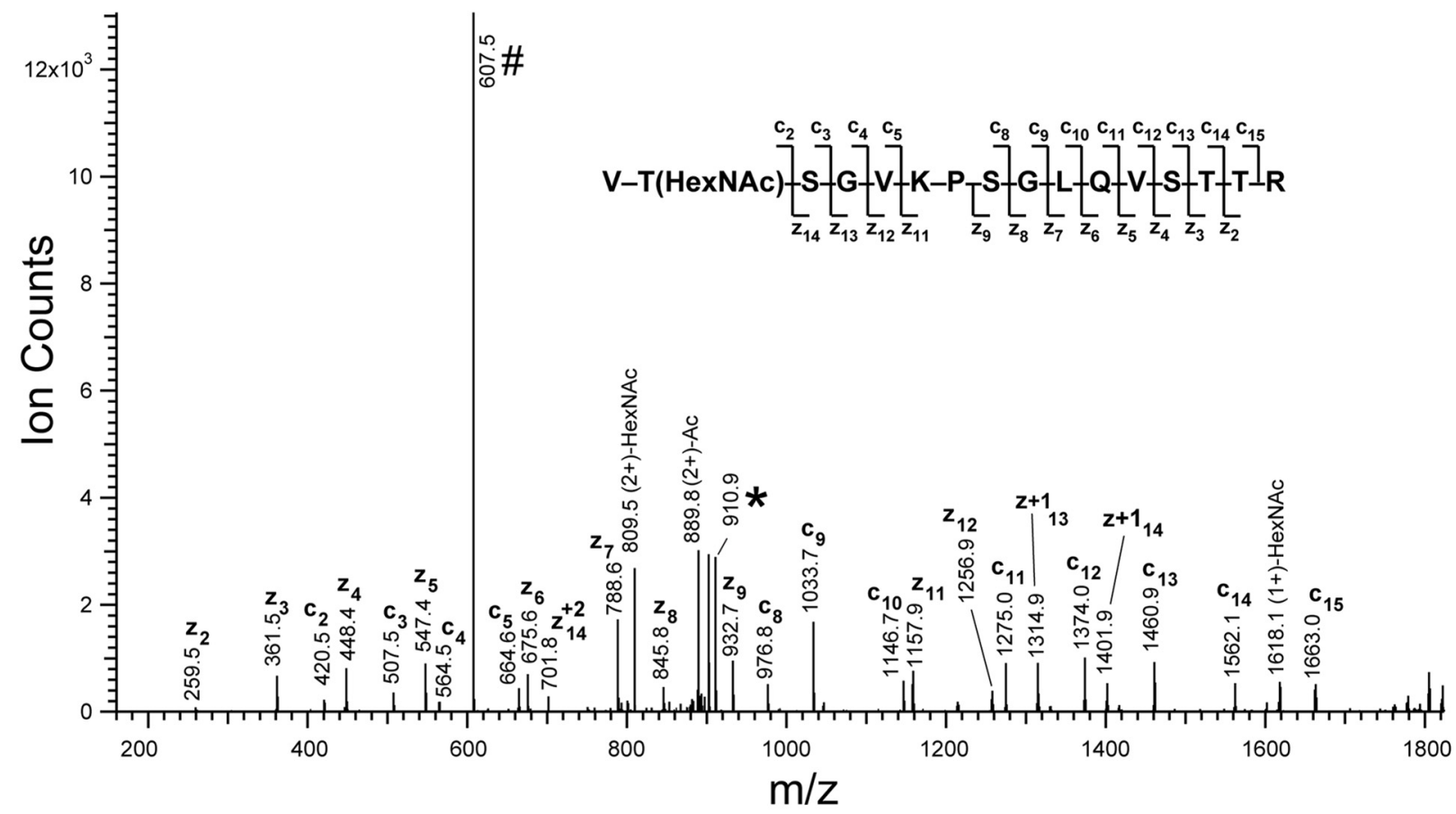

C

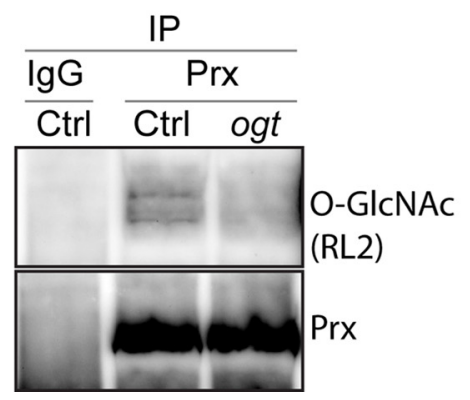

D

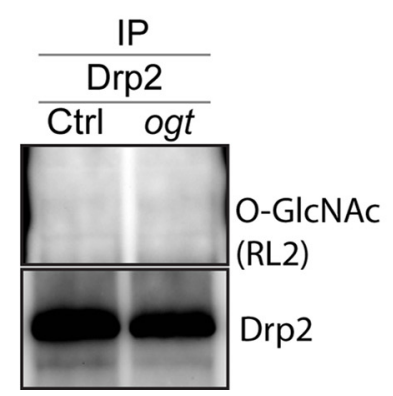

E

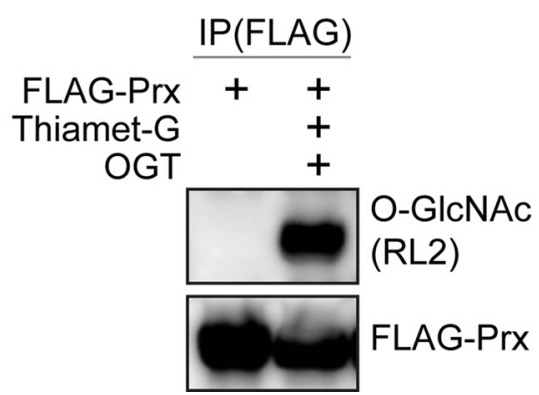

Figure 4. PRX is 0-GICNAcylated at multiple sites by OGT. $A$, Schematic representation of PRX domains, 0-GIcNAcylation sites, and residues mutated in hereditary neuropathy. Three 0-GIcNAcylated PRX peptides (red) and five 0-GIcNAcylated Ser and Thr residues (asterisks) were identified by mass spectrometry (MS/ETD) analysis of rat sciatic nerve 0-GIcNAc proteome. PRX functional domains and sequence features are indicated in blue. Human PRX mutations associated with CMT4F and DSS are indicated in magenta. B, ETD spectrum of precursor ion 607.3303 ( $3+$ ) $\mathrm{m} / \mathrm{z}$ identified as the PRX peptide 1050-VTSGVKPSGLQVSTTR-1065 0-GICNAcylated (HexNAc) at Thr-1065. ETD fragment ions are labeled (c and z) and depicted on the peptide sequence. The precursor ion (\#) and its charge-reduced form ( $^{*}$ ) are also indicated. C, D, Western blot analysis of PRX 0-GICNAcylation in sciatic nerves from 1-month-old (trl and OGT-SCKO (ogt) mice. Nerve lysates were immunoprecipitated using PRX, DRP2, or control lgG antibodies. 0-GICNAcylation, PRX, and DRP2 were detected by Western blotting with anti-0-GICNAc RL2, anti-PRX-N, and anti-DRP2 antibodies, respectively (as indicated). Note 0-GIcNAcylated PRX in sciatic nerve lysates from Ctrl but not from 0GT-SCKO (ogt) mice. 0-GIcNAcylation of DRP2 is undetectable both in control and OGT-SCKO nerve lysates. E, Western blot analysis of PRX 0-GIcNAcylation in HEK 293T cells. FLAG-tagged PRX (FLAG-Prx) is 0-GIcNAcylated in HEK 293T cells expressing exogenous OGT and treated with the OGA inhibitor Thiamet-G. IP, Immunoprecipitation.

PRX-expressing HEK 293 cells treated with the OGA inhibitor Thiamet-G and transfected with OGT (Fig. 4E).

Phenotype of OGT-SCKO and Prx-deficient mice are similar Recessively inherited PRX mutations are causally associated with the human peripheral neuropathy syndromes CMT4F and DSS (Fig. 4A). The morphological and clinical features present in patients with CMT4F and DSS include tomacula formation, demy- elination, axonal loss, and abnormal motor and sensory nerve conduction studies (Renouil et al., 2013). These symptoms are similar to those observed in OGT-SCKO mice, as well as those previously reported in studies of Prx-deficient mice (Gillespie et al., 2000). Indeed, we find striking similarities in the phenotypes of OGT-SCKO and Prx mutant mice. We directly compared nerve pathology in these mice at 1,3, and 9 months of age. We found no significant axon loss or morphological abnormalities in 
1-month-old animals of either genotype. We observed extensive tomacula formation and moderate axon loss starting at 2-3 months of age in both Prx and OGT-SCKO mutant mice (Fig. $5 A$ ). At 9 months of age, axonal loss was severe in both mutants, and there was evidence of hypomyelination/demyelination (Fig. $5 A)$. Quantification of the myelinated axons per nerve $(n=3$ for each genotype) revealed that the progression of axon loss in both mutants was very similar. At 3 months, the number of myelinated axons per nerve is $4255 \pm 79$ in wild-type mice, $3585 \pm 101(15 \%$ loss) in $\operatorname{Prx}$ mutant mice, and $3478 \pm 142$ (18\% loss) in OGTSCKO mice. At 9 months, the number of myelinated axons per nerve is $4046 \pm 201$ in wild-type mice, $2497 \pm 134$ (38\% loss) in Prx mutant mice, and $2597 \pm 167$ (35\% loss) in OGT-SCKO mice. These similarities suggest a common pathogenic mechanism underlying the progression and severity of the tomaculous demyelinating peripheral neuropathy in these mutants (Gillespie et al., 2000). Together with the identification of PRX as an O-GlcNAcylated protein in our MS/ETD study, these phenotypic parallels led us to hypothesize that disruption of PRX function in OGT-SCKO mice contributes to the development of their peripheral neuropathy.

We investigated whether specific functions of PRX are disrupted in OGT-SCKO mice. DRP2 directly interacts with PRX, and together they form a complex with Dystroglycan at the abaxonal (outer surface) appositions located between compact myelin and SC plasma membrane along myelinated fibers (Sherman et al., 2001). Interestingly, DRP2 is no longer localized to these abaxonal appositions in Prx-deficient mice (Sherman et al., 2001). We therefore examined whether SC O-GlcNAcylation affects DRP2 subcellular localization using immunohistochemistry on teased fiber preparations of sciatic nerves. In control nerves, DRP2 localizes to spheroidal clusters along the myelinated fibers (Fig. $5 B$ ), representing its concentration at abaxonal appositions (Sherman et al., 2001, 2012). However, few DRP2-postive appositions are observed in OGT-SCKO nerves; instead, the majority of DRP2 is diffusely distributed around the SC perinuclear cytoplasm (Fig. 5B). This mislocalization of DRP2 in the OGT-SCKO nerves is highly reminiscent of Prx mutant nerves (Sherman et al., 2001, 2012), indicating that O-GlcNAcylation in SCs is important for the formation of abaxonal membrane appositions.

The free flow of molecules within the SC cytoplasm occurs via small channels known as Cajal bands that are demarcated by the abaxonal appositions that lie between compact myelin and the plasma membrane. We used electron microscopy to further investigate the effects of OGT loss on abaxonal membrane appositions. At 1 month of age, there are, on average, three membrane appositions per myelinated axon in control mice (Fig. 5C, Ctrl, arrowheads; Court et al., 2004). In contrast, the majority of SCs in OGT-SCKO nerves lack these appositions and hence the normal compartmentalization of their cytoplasm (Fig. $5 C, D$ ). Instead, the SC cytoplasmic space runs around the entire circumference of the axon, similar to the situation in myelinated fibers of Prx mutant mice (Court et al., 2004). This deficit indicates that SC O-GlcNAcylation is critical for formation of abaxonal appositions of the myelin sheath and hence the establishment of cytoplasmic channels (Cajal bands) along myelinated fibers.

In addition to its role in abaxonal apposition formation, PRX controls the cell-autonomous process of SC elongation along the length of the myelinated fiber as demonstrated by the shortened internodes in nerves of Prx mutant mice (Court et al., 2004). Importantly, Drp2 mutant mice have normal internodal distances (Sherman et al., 2012); thus, in contrast to formation of abaxonal appositions, PRX-dependent SC elongation does not require DRP2. To test whether SC elongation is affected in OGTSCKO mice, we quantified the internodal lengths in sciatic nerve fibers. Teased fiber preparations were immunostained with antibodies to the voltage-gated sodium channel (NAV1.6) to identify nodes of Ranvier and MBP to mark the internodes (see representative image in Fig. $5 E$ ). The average internodal length in OGT-SCKO mice was $344 \pm 202 \mu \mathrm{m}$ versus $733 \pm 115 \mu \mathrm{m}$ in littermate control mice (Student's $t$ test, $p<0.001, n=3$ mice per genotype and 10 fibers per mouse). The significant shortening of the internode is strikingly reminiscent of that observed in Prx mutant mice (Court et al., 2004) and implies that O-GlcNAcylation is required for the PRXdependent SC elongation process. Furthermore, O-GlcNAcylation affects PRX functions that are independent of DRP2, indicating that lack of O-GlcNAcylation in SCs leads to defects in both DRP2dependent and -independent PRX functions.

\section{O-GlcNAcylation promotes PRX localization at abaxonal appositions along mature myelinated fibers}

Several important functions of PRX appear to be disrupted by lack of O-GlcNAcylation, but how this modification promotes PRX activity is unclear. Some transcription factors are stabilized by O-GlcNAcylation; thus, OGT deficiency can lead to decreased protein levels through enhanced degradation (Cheng and Hart, 2001; Zhang et al., 2003; Zhu et al., 2015). To test whether PRX might be destabilized by lack of O-GlcNAC modification, we examined its expression in sciatic nerves from 1-month-old OGT-SCKO mice. PRX was present at roughly equivalent levels in OGT-SCKO versus littermate control sciatic nerve (Fig. 6A, $B$ ). Although there was a slight, statistically insignificant decrease $(\sim 15 \%)$ in the mutant nerve, it is unlikely to be functionally important as humans and mice heterozygous for mutant $P R X$ alleles do not manifest any abnormalities (Gillespie et al., 2000; Renouil et al., 2013). Hence, changes in PRX stability caused by lack of O-GlcNAcylation cannot explain the nerve phenotype in OGT-SCKO mice.

We expanded our Western blot analysis to include other proteins associated with PRX. Strikingly, the level of DRP2, the only protein known to interact directly with PRX, was significantly decreased in sciatic nerves from 1-month-old OGT-SCKO mice (Fig. 6A,B). In contrast, levels of Dystroglycan $\alpha$, another component of the DRP2-Dystroglycan complex at the SC plasma membrane, were unchanged in OGT-SCKO nerves. The lower level of DRP2 in OGT-SCKO mice is similar to the specific and concomitant loss of DRP2 in Prx mutant mice; further supporting the idea that SC O-GlcNAcylation deficiency mimics loss of PRX function. Notably, DRP2 from OGT-SCKO nerve lysates migrated faster on SDS-PAGE than DRP2 from control nerve lysates. This increased DRP2 electrophoretic mobility was also observed in Prx mutant mice and is attributable to reduced DRP2 phosphorylation (Sherman et al., 2012). The interaction between PRX and DRP2 is thought to be necessary for DRP2 phosphorylation (Sherman et al., 2012), suggesting that O-GlcNAcylation might regulate the DRP2-PRX interaction.

In addition to DRP2 phosphorylation, its interaction with PRX is required for formation of abaxonal appositions in myelinated fibers (Sherman et al., 2012). To investigate whether PRX modification by O-GlcNAcylation alters its interaction with DRP2, we performed coimmunoprecipitation experiments using sciatic nerve lysates from 1-month-old control and OGT-SCKO mice (Fig. 6C,D). We found that unmodified PRX was still capable of binding DRP2, although there was a slight but reproducible decrease in the interaction between PRX and DRP2 in OGT-SCKO nerve. These results indi- 
A

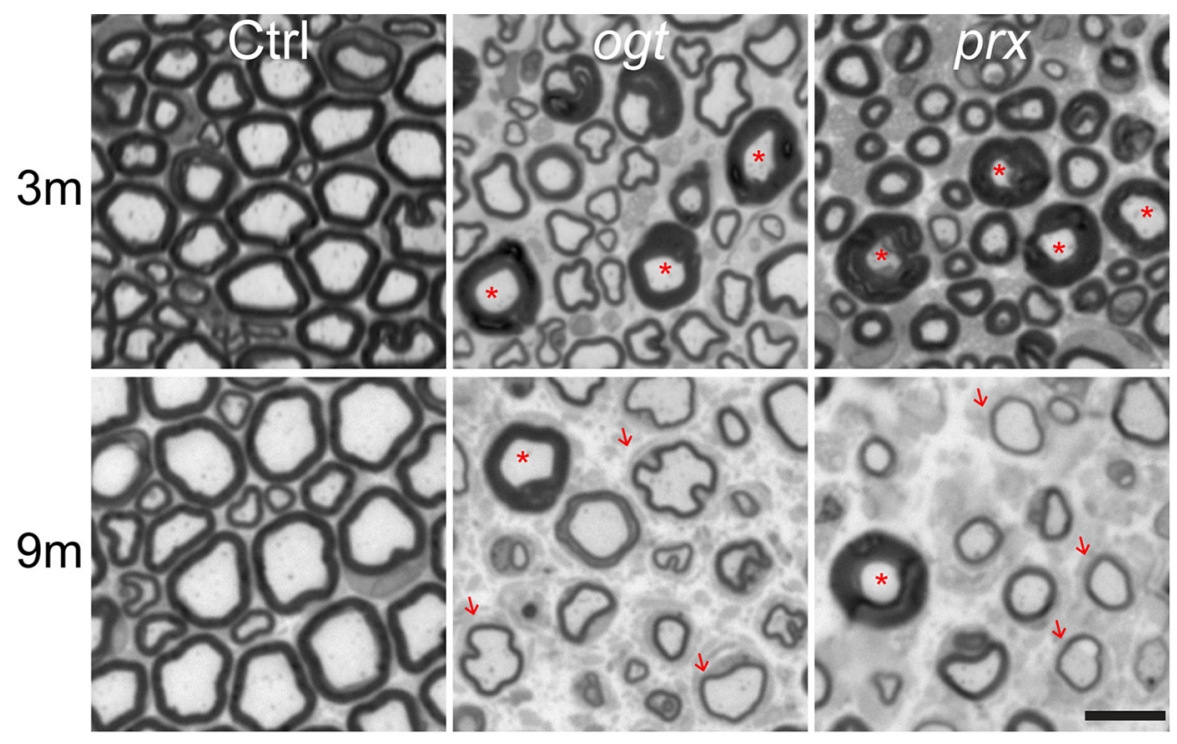

B
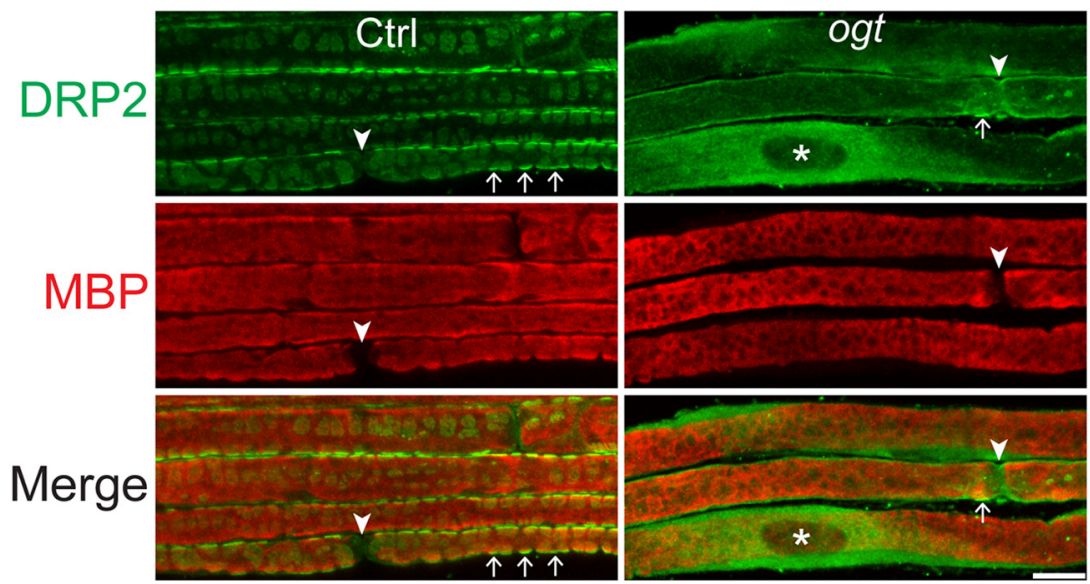

C
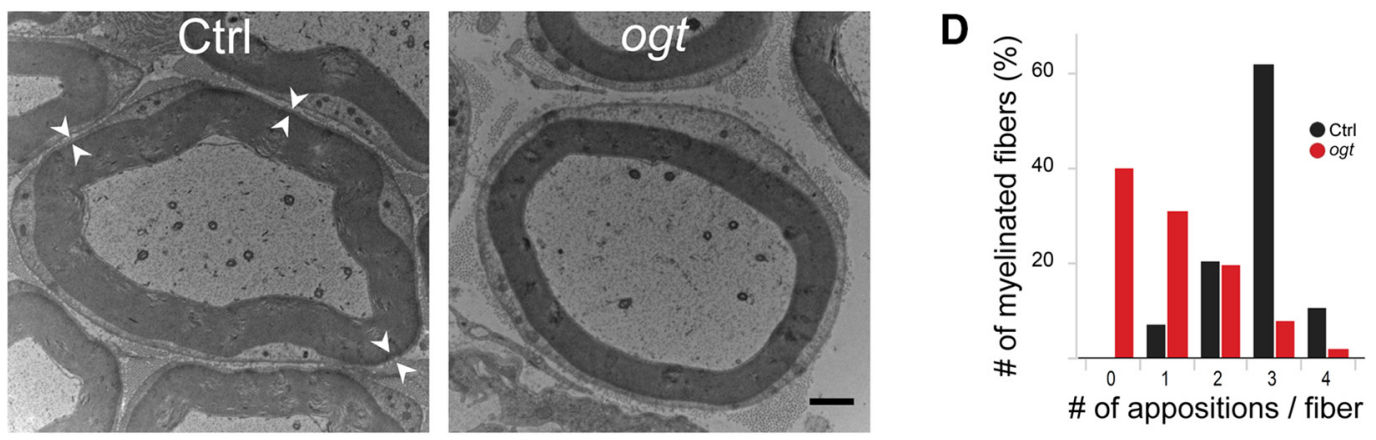

E

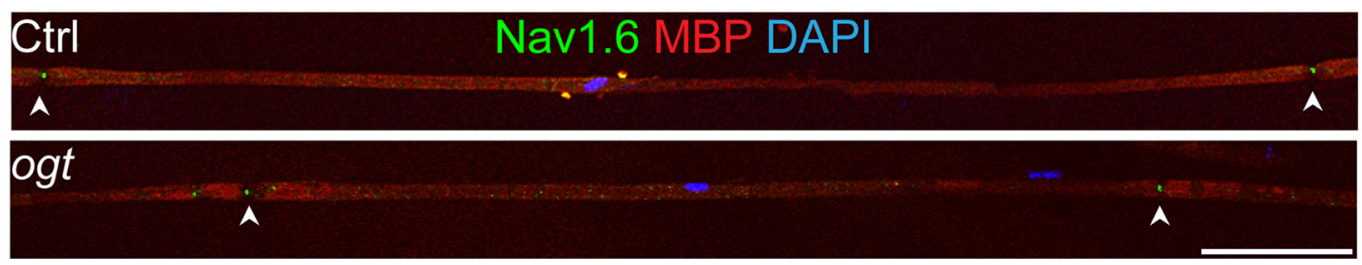

Figure 5. Abaxonal apposition formation and internodal length are abnormal in OGT-SCKO nerves. A, Representative toluidine blue-stained semithin cross sections of sciatic nerves from Ctrl, OGT-SCKO (ogt), and Prx-null ( $p r x$ ) mice at 3 and 9 months of age. Note the decrease in the number of axons in the mutant animals and the presence of tomacula (asterisks) and thinly myelinated fibers (arrows). Scale bar, $10 \mu \mathrm{m}$. B, Representative confocal microscopic images of teased sciatic nerve fibers from 1-month-old OGT-SCK0 and control mice labeled for DRP2 (green) and MBP (red). Abaxonal appositions (arrows). Note the diffuse DRP2 staining and paucity of appositions in OGT-SCKO nerve. The nodes of Ranvier (arrowheads) and the SC nucleus (asterisk) are labeled. Scale bar, $10 \mu \mathrm{m}$. C, Electron micrograph showing myelinated fibers of sciatic nerve in a cross section from 1-month-old control and OGT-SCKO mice. Pairs of arrowheads mark the abaxonal appositions residing between the compact myelin and SC plasma membrane. Note the lack of abaxonal appositions in the OGT-SCKO fiber. Scale bar, $1 \mu \mathrm{m}$. D, Quantification of abaxonal appositions displayed as average per myelinated fiber in nerves from $\boldsymbol{B}$. Note the dramatic decrease in appositions in OGT-SCKO mice. Approximately 30 fibers per mouse were analyzed; $n=3$ mice per genotype. E, Representative confocal microscopic images depicting the entire internodal length of myelinated fibers from 3-month-old control and OGT-SCKO nerves labeled for NAV1.6 (green), MBP (red), and DAPI (blue). Note the decrease in intermodal length in the 0GT-SCK0 nerve ( $n=3$ mice per genotype, 10 fibers per mouse). Arrowheads mark the node of Ranvier. Scale bar, $100 \mu \mathrm{m}$. 
A

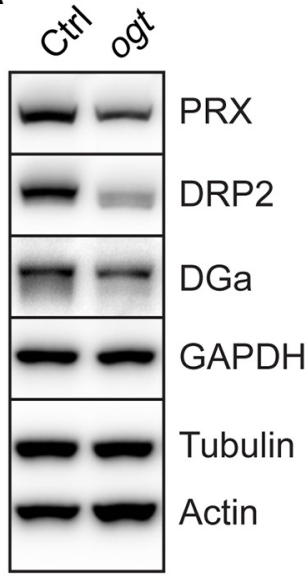

B

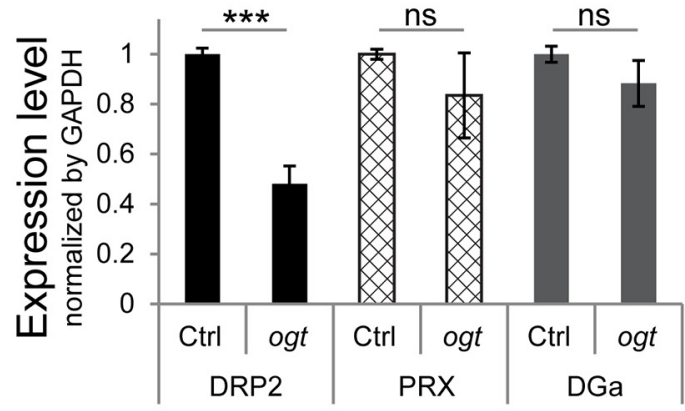

C

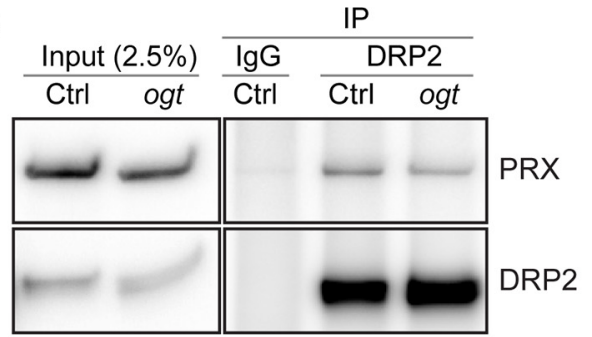

D

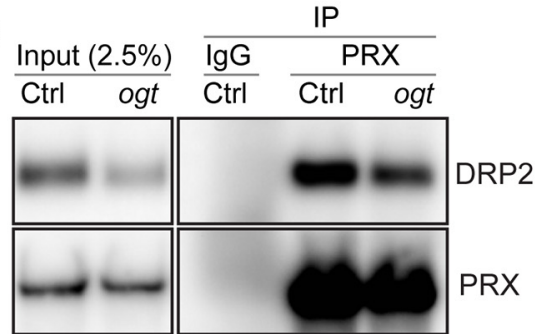

E

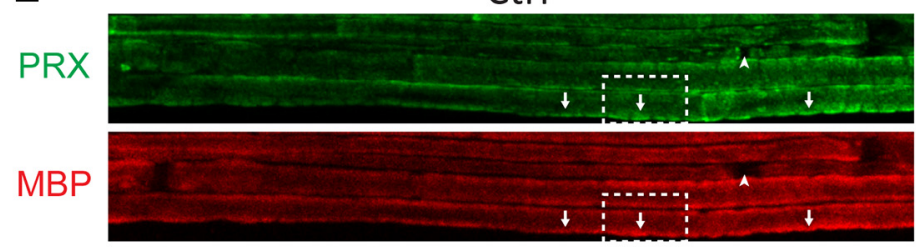

Ctrl

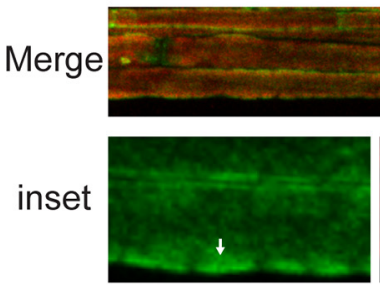

F
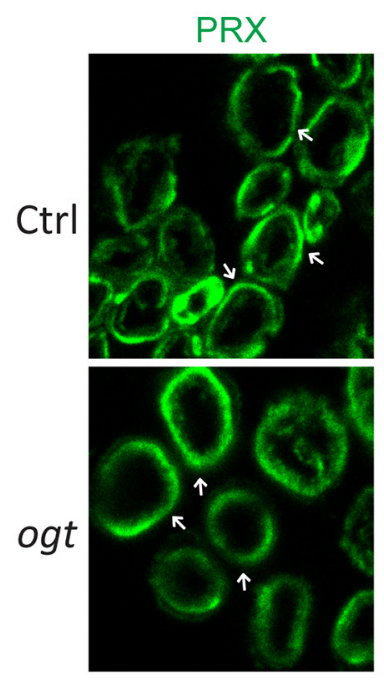
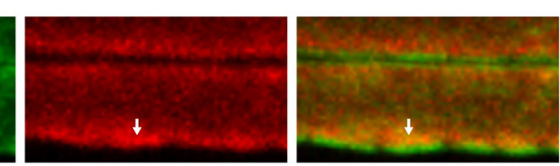
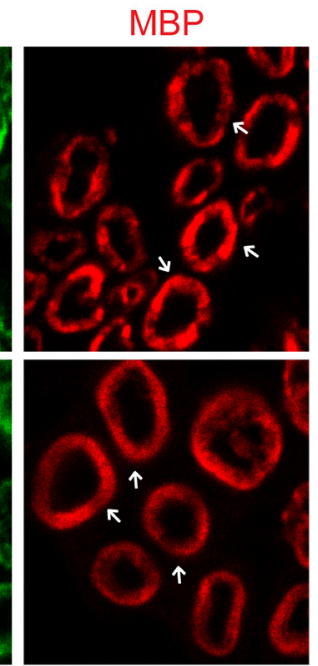

ogt
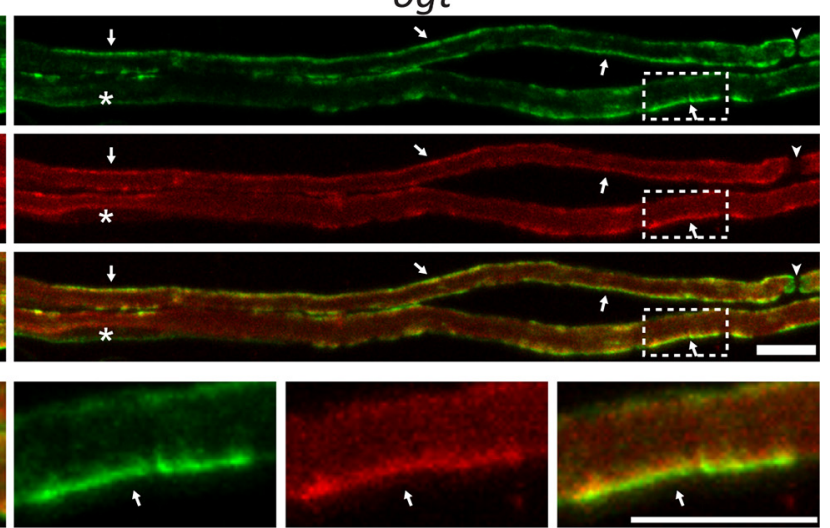
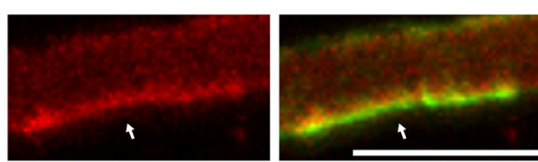

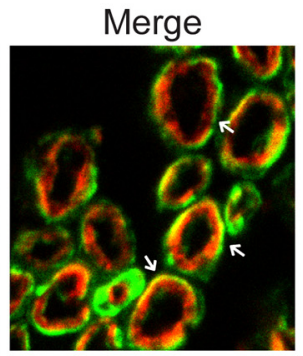

G
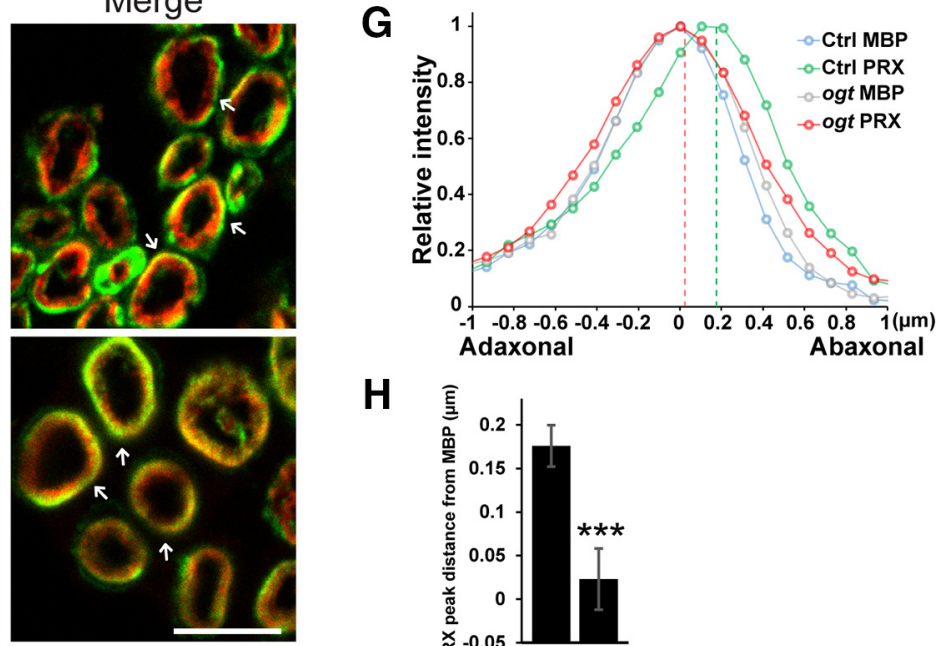

H

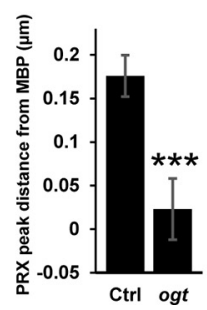

Figure 6. 0 -GICNAcylation is required for proper PRX localization but does not affect DRP2-PRX interaction. $\boldsymbol{A}$, Western blot analysis of PRX, DRP2, and $\alpha$-Dystroglycan in sciatic nerves from 1-month-old control and OGT-SCKO mice. DGa, $\alpha$-Dystroglycan; GAPDH, glyceraldehyde-3-phosphodehydrogenase; Actin, $\beta$-actin; Tubulin, $\beta$-tubulin. Note the decrease in the DRP2 level in the OGT-SCKO nerve. B, Quantification of PRX, DRP2, and DGa in $\boldsymbol{A}$. Normalized by GAPDH ( $n=3$ mice per genotype). Data are represented as mean \pm SEM. Student's $t$ test, $\left.{ }^{* * *} p<0.001\right)$; $n s$, not significant. C, $\boldsymbol{D}$, Coimmunoprecipitation analysis of interaction between PRX and DRP2. Nerve lysates were immunoprecipitated for DRP2 ( $\boldsymbol{C}$ ) or PRX (D). The bound partner was detected by Western blotting with indicated antibody. IP, Immunoprecipitation; IgG, preimmune rabbit sera. A total of $2.5 \%$ of the lysate was used for input control (Input). Note that the PRX-DRP2 interaction was maintained in OGT-SCKO nerve lysates. $\boldsymbol{E}-\boldsymbol{H}$, Localization of PRX in Ctrl and OGT-SCKO (ogt) sciatic nerves. $\boldsymbol{E}$, $\boldsymbol{F}$, Representative confocal microscopic images of teased fibers $(\boldsymbol{E})$ and cross sections $(\boldsymbol{F})$, stained for PRX (green) and MBP (red). $\boldsymbol{E}$, In teased fiber preparations, PRX distributes as elongated coarse streaks (arrows) along the myelin sheath in OGT-SCKO nerves, whereas it localizes to apposition-like features (arrows) in controls. The nodes of Ranvier (arrowheads) and the SC nucleus (asterisk) are labeled. The area enclosed by the dashed line (inset) was enlarged to highlight appositions in control and the corresponding area in the mutant. $\boldsymbol{F}$, In cross sections, PRX concentrates peripherally to MBP (arrows) in control nerves, whereas PRX and MBP overlap extensively in OGT-SCKO nerves. G, Line-plot profile of PRX and MBP distribution across the myelin sheath in $\boldsymbol{F}$. Pixel intensities of PRX and MBP on a straight line drawn across the (Figure legend continues.) 
cate that the O-GlcNAcylation state does not have a major effect on DRP2-PRX complex formation.

PRX has a more widespread distribution than DRP2 within the nerve: it first translocates from the nucleus to the adaxonal (inner) surface and, as SCs mature, is later found on the abaxonal surface of the myelin sheath (Gillespie et al., 1994; Scherer et al., 1995; Sherman and Brophy, 2000; Sherman et al., 2001). We next examined whether the lack of O-GlcNAcylation alters PRX subcellular localization (Fig. 6E-H). We consistently found that PRX is localized to membrane appositions in control nerves (Fig. 6E), although it is more diffusively distributed than DRP2 (Fig. 5B). In OGT-SCKO nerves, PRX is diffusely localized at the abaxonal surface but is present in elongated patches with ill-defined borders, suggesting a role of O-GlcNAcylation in the localization of PRX at a late stage of myelination. In cross sections, a significant fraction of PRX can clearly be seen peripheral to the MBP distribution in control nerves (Fig. 6F). However, in OGT-SCKO nerves, PRX distributed diffusively and overlapped with MBP throughout the width of the myelin sheath. By quantification of the relative distribution of PRX to MBP across the myelin sheath (Fig. 6G,H), we confirmed the extensive overlap between PRX and MBP in OGT-SCKO nerves as well as the clearly segregated distribution in wild-type nerves. In particular, the demarcated peak distribution of PRX and MBP normally observed in wildtype nerves is lost in OGT-SCKO nerves (Fig. 6H). In summary, these observations indicate that O-GlcNAc modification is required for proper localization of PRX to abaxonal appositions in myelinated fibers.

\section{Discussion}

Our studies reveal a crucial role for SC O-GlcNAcylation in mediating axon-glial interactions in the peripheral nervous system. Importantly, SCs with deficient O-GlcNAcylation did not form normal myelin or provide adequate support to maintain axon integrity. In a mass spectrometry analysis of the O-GlcNAc proteome in rat sciatic nerve, we identified the myelin protein PRX as an O-GlcNAcylated protein. The OGT-SCKO and Prx mutant mice both develop tomaculous demyelinating peripheral neuropathy with similar features. Furthermore, specific functions of PRX were impaired in OGT-SCKO nerves, including the formation of membrane appositions and Cajal bands as well as the shortened internodes reflective of poor SC elongation.

\section{OGT-SCKO mice as a model of tomaculous demyelinating peripheral neuropathy}

Tomacula, focal thickenings of myelin, are a peculiar clinical manifestation that is observed in a number of inherited demyelinating peripheral neuropathies. Several mechanisms have been proposed to explain tomacula formation, including hypermyelination, formation of redundant myelin loops, presence of a second mesaxon, transnodal myelination, multiple SCs forming one myelin sheath, and myelin sheath disruption (Sander et al., 2000). In OGT-SCKO nerves, tomacula are mostly infoldings and outfoldings of the myelin sheath and are localized at the jux-

\section{$\leftarrow$}

(Figure legend continued.) myelin sheath were first aligned according to the peak coordinate of MBP per genotype, then averaged and normalized to the max intensity per protein. Note that PRX and MBP extensively overlap in OGT-SCKO nerves but are segregated in control nerves. $\boldsymbol{H}$, Quantification of the location of PRX peaks from MBP in G. Twenty myelinated fibers from three mice per genotype were examined. Data are represented as mean \pm SEM. Student's $t$ test, ${ }^{* * *} p<0.001$. Scale bars: $\boldsymbol{E}, 10 \mu \mathrm{m} ; \boldsymbol{F}, 5 \mu \mathrm{m}$. taparanodal/paranodal regions. Tomacula formation in OGTSCKO sciatic nerves begins at $\sim 6$ weeks of age and peaks at $\sim 3-4$ months. This timing is similar to that observed in Prx mutant mice. However, it is distinct from the early postnatal appearance of tomacula in Pmp22 mutant mice that serve as a model of HNPPs, which is associated with tomacula formation (Adlkofer et al., 1995; Gillespie et al., 2000). Tomaculous neuropathy is also observed in mice with SC-specific loss of Pten and correspondingly increased levels of pAkt (Goebbels et al., 2012). In accord, the myelin abnormalities in these nerves are suppressed by treating with rapamycin to inhibit mechanistic target of rapamycin. In contrast, pAkt levels are not increased in OGT-SCKO nerves and nerve abnormalities in OGT-SCKO mice are not rescued by rapamycin treatment (data not shown). Clearly, tomacula can form through perturbation of multiple pathways, and developing effective treatments will require an understanding of how these pathways intersect to cause myelin overgrowth.

The functional consequences of tomacula formation are perplexing despite the simplified assertion of tomacula as a myelin abnormality. Studies from many years ago demonstrated that relative myelin thickness, as measured via g-ratios, is carefully calibrated for optimal effective nerve conduction (Smith and Koles, 1970). This implies that alterations from the normal g-ratios in disease conditions will result in slower conduction velocity, such as that which occurs in the absence of OGT. However, in our physiological studies, we found that nerve conduction deficits begin before the development of tomacula. In addition, moderate conduction velocities were maintained even as the number of tomacula continued to increase dramatically with age. Similarly, nerve function in Drp2 mutant mice remained normal despite an age-dependent increase in tomacula formation (Sherman et al., 2012). Overall, these observations imply that tomacula formation itself does not necessarily cripple peripheral nerve function and that additional damage must occur to affect conduction velocity.

\section{O-GlcNAc regulation of PRX in myelinating SCs}

In our mass spectrometry analysis of the rat sciatic nerve O-GlcNAc proteome, we identified PRX as a SC-specific O-GlcNAcylated protein. An important molecular aspect of PRX is its concentration at the abaxonal appositions along the myelin fibers (Gillespie et al., 1994). In this study, we showed that the localization of PRX is an O-GlcNAcylation-dependent process in that PRX lacking this modification is not properly localized. The lack of O-GlcNAcylation did not significantly alter PRX levels or its interaction with DRP2; thus, these two mechanisms cannot be invoked to explain how O-GlcNAcylation mediates PRX localization. Speculatively, O-GlcNAcylation of PRX may alter the accessibility of a potential interface that is necessary to interact with the translocation machinery. To address this problem, mutational studies to identify the critical O-GlcNAcylated residues required for PRX localization will be necessary along with other studies to identify proteins involved in this process.

Our proteomic analysis did not identify O-GlcNAc modification of other abundant myelin proteins (e.g., MPZ, PMP22); however, we did find other O-GlcNAcylated proteins in the nerve that are expressed by SCs and whose function could be affected by mutation of OGT. Altered function of these proteins could also contribute to the neuropathy observed in OGT-SCKO mice. With regard to PRX, its role in the formation of Cajal bands, which are SC cytoplasm-filled channels, suggests that it could play a unique role in coupling metabolism to myelin maintenance and nerve function (Nave, 2010). For example, because 
glucose and other metabolites are primarily sealed from the axon by the myelin sheath, these channels constitute an access point for axonal energy sources and could provide a mechanism for PRX regulation of axonal stability. Furthermore, microtubule-based transport in Cajal bands has been proposed to promote SC elongation, another PRX-dependent process, that accompanies axonal growth (Court et al., 2004). OGT, which is regulated by glucose concentration, provides a means to connect SC metabolism with the PRX-dependent processes involved in myelin formation/maintenance. In this scenario, O-GlcNAc-dependent localization of PRX at the abaxonal (outer) surface of the myelinated fiber would signal that the metabolic environment is sufficient for the SC to engage in myelination and provide axonal support. This may be important in diseases caused by altered metabolism such as in mitochondrial deficiency syndromes and diabetes, both of which are frequently associated with peripheral neuropathy.

In summary, this study identifies OGT activity as an important regulator of SC functions such as myelin maintenance and axonal support. We further propose that O-GlcNAcylation of PRX contributes to the OGT regulation of SC function. We anticipate that the OGT-SCKO mice will be useful in understanding how SC metabolism contributes to PNS function and, perhaps, in developing new strategies for treating peripheral neuropathy by targeting SC function.

\section{Notes}

Supplemental material for this article is available at http://prospector2.ucsf. $\mathrm{edu} /$ prospector/cgi-bin/msform.cgi?form $=$ msviewer. O-GlcNAc proteme of rat sciatic nerve can be viewed in MS_Viewer at the provided website (search keys: ETD, ntrqixzaiv; HCD, fcx3docywo) This material has not been peer reviewed.

\section{References}

Adlkofer K, Martini R, Aguzzi A, Zielasek J, Toyka KV, Suter U (1995) Hypermyelination and demyelinating peripheral neuropathy in Pmp22deficient mice. Nat Genet 11:274-280. CrossRef Medline

Baker PR, Chalkley RJ (2014) MS-viewer: a web-based spectral viewer for proteomics results. Mol Cell Proteomics 13:1392-1396. CrossRef Medline

Beirowski B, Babetto E, Golden JP, Chen YJ, Yang K, Gross RW, Patti GJ, Milbrandt J (2014) Metabolic regulator LKB1 is crucial for Schwann cell-mediated axon maintenance. Nat Neurosci 17:1351-1361. CrossRef Medline

Bond MR, Hanover JA (2013) O-GlcNAc cycling: a link between metabolism and chronic disease. Annu Rev Nutr 33:205-229. CrossRef Medline

Bond MR, Hanover JA (2015) A little sugar goes a long way: the cell biology of O-GlcNAc. J Cell Biol 208:869-880. CrossRef Medline

Cheng X, Hart GW (2001) Alternative O-glycosylation/O-phosphorylation of serine-16 in murine estrogen receptor beta: post-translational regulation of turnover and transactivation activity. J Biol Chem 276:10570-10575.

Corfas G, Velardez MO, Ko CP, Ratner N, Peles E (2004) Mechanisms and roles of axon-Schwann cell interactions. J Neurosci 24:9250-9260. CrossRef Medline

Court FA, Sherman DL, Pratt T, Garry EM, Ribchester RR, Cottrell DF, Fleetwood-Walker SM, Brophy PJ (2004) Restricted growth of Schwann cells lacking Cajal bands slows conduction in myelinated nerves. Nature 431:191-195. CrossRef Medline

Dytrych L, Sherman DL, Gillespie CS, Brophy PJ (1998) Two PDZ domain proteins encoded by the murine periaxin gene are the result of alternative intron retention and are differentially targeted in Schwann cells. J Biol Chem 273:5794-5800. CrossRef Medline

Feltri ML, D’antonio M, Previtali S, Fasolini M, Messing A, Wrabetz L (1999) P0-Cre transgenic mice for inactivation of adhesion molecules in Schwann cells. Ann N Y Acad Sci 883:116-123. CrossRef Medline

Fünfschilling U, Supplie LM, Mahad D, Boretius S, Saab AS, Edgar J, Brinkmann BG, Kassmann CM, Tzvetanova ID, Möbius W, Diaz F, Meijer D,
Suter U, Hamprecht B, Sereda MW, Moraes CT, Frahm J, Goebbels S, Nave KA (2012) Glycolytic oligodendrocytes maintain myelin and longterm axonal integrity. Nature 485:517-521. CrossRef Medline

Gillespie CS, Sherman DL, Blair GE, Brophy PJ (1994) Periaxin, a novel protein of myelinating Schwann cells with a possible role in axonal ensheathment. Neuron 12:497-508. CrossRef Medline

Gillespie CS, Sherman DL, Fleetwood-Walker SM, Cottrell DF, Tait S, Garry EM, Wallace VC, Ure J, Griffiths IR, Smith A, Brophy PJ (2000) Peripheral demyelination and neuropathic pain behavior in periaxin-deficient mice. Neuron 26:523-531. CrossRef Medline

Goebbels S, Oltrogge JH, Wolfer S, Wieser GL, Nientiedt T, Pieper A, Ruhwedel T, Groszer M, Sereda MW, Nave KA (2012) Genetic disruption of Pten in a novel mouse model of tomaculous neuropathy. EMBO Mol Med 4:486-499. CrossRef Medline

Hahne H, Sobotzki N, Nyberg T, Helm D, Borodkin VS, van Aalten DM, Agnew B, Kuster B (2013) Proteome wide purification and identification of O-GlcNAc-modified proteins using click chemistry and mass spectrometry. J Proteome Res 12:927-936. CrossRef Medline

Halim A, Westerlind U, Pett C, Schorlemer M, Rüetschi U, Brinkmalm G, Sihlbom C, Lengqvist J, Larson G, Nilsson J (2014) Assignment of saccharide identities through analysis of oxonium ion fragmentation profiles in LC-MS/MS of glycopeptides. J Proteome Res 13:6024-6032. CrossRef Medline

Hart GW, Akimoto Y (2009) The O-GlcNAc modification. In: Essentials of glycobiology Chap 18 (Varki A, Cummings RD, Esko JD, Freeze HH, Stanley P, Bertozzi CR, Hart GW, Etzler ME, eds). Cold Spring Harbor, NY: Cold Spring Harbor Laboratory.

Maddala R, Skiba NP, Lalane R, Sherman DL, Brophy PJ, Rao PV (2011) Periaxin is required for hexagonal geometry and membrane organization of mature lens fibers. Dev Biol 357:179-190. CrossRef Medline

Nave K-A (2010) Myelination and the trophic support of long axons. Nat Rev Neurosci 11:275-283. CrossRef Medline

Norrmén C, Figlia G, Lebrun-Julien F, Pereira JA, Trötzmüller M, Köfeler HC, Rantanen V, Wessig C, van Deijk AL, Smit AB, Verheijen MH, Rüegg MA, Hall MN, Suter U (2014) mTORC1 controls PNS myelination along the mTORC1-RXR $\gamma$-SREBP-lipid biosynthesis axis in Schwann cells. Cell Rep 9:646-660. CrossRef Medline

O'Donnell N, Zachara NE, Hart GW, Marth JD (2004) Ogt-dependent $\mathrm{X}$-chromosome-linked protein glycosylation is a requisite modification in somatic cell function and embryo viability. Mol Cell Biol 24:16801690. CrossRef Medline

Ozcan S, Andrali SS, Cantrell JE (2010) Modulation of transcription factor function by O-GlcNAc modification. Biochim Biophys Acta 1799:353364. CrossRef Medline

Patzig J, Jahn O, Tenzer S, Wichert SP, de Monasterio-Schrader P, Rosfa S, Kuharev J, Yan K, Bormuth I, Bremer J, Aguzzi A, Orfaniotou F, Hesse D, Schwab MH, Möbius W, Nave KA, Werner HB (2011) Quantitative and integrative proteome analysis of peripheral nerve myelin identifies novel myelin proteins and candidate neuropathy loci. J Neurosci 31:16369_ 16386. CrossRef Medline

Pooya S, Liu X, Kumar VB, Anderson J, Imai F, Zhang W, Ciraolo G, Ratner N, Setchell KDR, Yoshida Y, Jankowski MP, Dasgupta B (2014) The tumour suppressor LKB1 regulates myelination through mitochondrial metabolism. Nat Commun 5:4993. CrossRef Medline

Renouil M, Stojkovic T, Jacquemont ML, Lauret K, Boué P, Fourmaintraux A, Randrianaivo H, Tallot M, Mignard D, Roelens P, Tabailloux D, Bernard R, Cartault F, Chane-Thien E, Dubourg O, Ferrer X, Sole G, Fournier E, Latour P, Lacour A, et al (2013) [Charcot-Marie-Tooth disease associated with periaxin mutations (CMT4F): clinical, electrophysiological and genetic analysis of 24 patients]. Rev Neurol (Paris) 169:603-612. CrossRef Medline

Sander S, Ouvrier RA, McLeod JG, Nicholson GA, Pollard JD (2000) Clinical syndromes associated with tomacula or myelin swellings in sural nerve biopsies. J Neurol Neurosurg Psychiatry 68:483-488. CrossRef Medline

Scherer SS, Xu YT, Bannerman PG, Sherman DL, Brophy PJ (1995) Periaxin expression in myelinating Schwann cells: modulation by axon-glial interactions and polarized localization during. Development 121:4265-4273. Medline

Shafi R, Iyer SP, Ellies LG, O’Donnell N, Marek KW, Chui D, Hart GW, Marth JD (2000) The O-GlcNAc transferase gene resides on the X chromo- 
some and is essential for embryonic stem cell viability and mouse ontogeny. Proc Natl Acad Sci U S A 97:5735-5739. CrossRef Medline

Shen Y-AA, Chen Y, Dao DQ, Mayoral SR, Wu L, Meijer D, Ullian EM, Chan JR, Lu QR (2014) Phosphorylation of LKB1/Par-4 establishes Schwann cell polarity to initiate and control myelin extent. Nat Commun 5:4991. CrossRef Medline

Sherman DL, Brophy PJ (2000) A tripartite nuclear localization signal in the PDZ-domain protein L-periaxin. J Biol Chem 275:4537-4540. CrossRef Medline

Sherman DL, Fabrizi C, Gillespie CS, Brophy PJ (2001) Specific disruption of a Schwann cell dystrophin-related protein complex in a demyelinating neuropathy. Neuron 30:677-687. CrossRef Medline

Sherman DL, Wu LMN, Grove M, Gillespie CS, Brophy PJ (2012) Drp2 and periaxin form Cajal bands with dystroglycan but have distinct roles in Schwann cell growth. J Neurosci 32:9419-9428. CrossRef Medline

Smith RS, Koles ZJ (1970) Myelinated nerve fibers: computed effect of myelin thickness on conduction velocity. Am J Physiol 219:1256-1258. Medline

Trinidad JC, Barkan DT, Gulledge BF, Thalhammer A, Sali A, Schoepfer R, Burlingame AL (2012) Global identification and characterization of both O-GlcNAcylation and phosphorylation at the murine synapse. Mol Cell Proteomics 11:215-229. CrossRef Medline

Viader A, Golden JP, Baloh RH, Schmidt RE, Hunter DA, Milbrandt J (2011)
Schwann cell mitochondrial metabolism supports long-term axonal survival and peripheral nerve function. J Neurosci 31:10128-10140. CrossRef Medline

Viader A, Sasaki Y, Kim S, Strickland A, Workman CS, Yang K, Gross RW, Milbrandt J (2013) Aberrant Schwann cell lipid metabolism linked to mitochondrial deficits leads to axon degeneration and neuropathy. Neuron 77:886-898. CrossRef Medline

Vosseller K, Trinidad JC, Chalkley RJ, Specht CG, Thalhammer A, Lynn AJ, Snedecor JO, Guan S, Medzihradszky KF, Maltby DA, Schoepfer R, Burlingame AL (2006) O-linked N-acetylglucosamine proteomics of postsynaptic density preparations using lectin weak affinity chromatography and mass spectrometry. Mol Cell Proteomics 5:923-934. CrossRef Medline

Wu LM, Williams A, Delaney A, Sherman DL, Brophy PJ (2012) Increasing internodal distance in myelinated nerves accelerates nerve conduction to a flat maximum. Curr Biol CB 22:1957-1961. CrossRef Medline

Zhang F, Su K, Yang X, Bowe DB, Paterson AJ, Kudlow JE (2003) O-GlcNAc modification is an endogenous inhibitor of the proteasome. Cell 115:715-725.

Zhu Y, Liu T-W, Cecioni S, Eskandari R, Zandberg WF, Vocadlo DJ (2015) O-GlcNAc occurs cotranslationally to stabilize nascent polypeptide chains. Nat Chem Biol 11:319-325. 